\title{
Medical Devices Biological Safety Assessment: Towards Animal-free Testing
}

\author{
Nadège Sachot \\ MA Animal Law and Society (UAB, Barcelona, Spain) \\ Augusto Vitale \\ Researcher in Animal Behaviour \\ Center for Behavioural Sciences and Mental Health \\ Istituto Superiore di Sanità, Roma, Italy
}

Received: December 2018

Accepted: January 2019

Recommended citation. SACHOT, N., VITALE, A., Medical Devices Biological Safety Assessment: Towards Animal-free Testing, dA. Derecho Animal (Forum of Animal Law Studies) 10/1 (2019) - DOI https://doi.org/10.5565/rev/da.392

\begin{abstract}
Animals have been used since a very long time as experimental subjects to support scientific progress and medical advances. Currently, various testing procedures implying animals are still being conducted within a broad range of scientific fields and applications, as for example the assessment of medical devices safety. The aim of this assessment is to investigate whether a medical device is safe for human use or poses a risk for patients' health. Animal testing for that purpose is especially encouraged by regulatory requirements, which prerequisite however that the use of such testing is deemed necessary and justified in the context of a risk management process. Thus, animal models are no longer systematically used as in the past, but they remain a cornerstone within the delicate decision-making process related to the marketing of medical devices. Though, animal testing has some critical limitations, such as ethical concerns and relevance of animal data, which challenge its further use to that objective. A particular attention is therefore currently given to the development of animal-free alternatives to better support the application of the 3Rs Principle (replacement, reduction, refining) within this field. Unfortunately, the highlyadvanced methods and technologies being developed face barriers (e.g. validation and standardization) which hinder and slow down their implementation as regulatory-accepted alternatives. To overcome these difficulties, the process of regulatory acceptance of these alternatives may be optimized. This may be achieved for example by improving the cooperation, coordination and communication between the different stakeholders, i.e. researchers, regulatory approval bodies and industries. Mostly, a special focus may be set on commitment and shared effort to enhance the efficiency of that process and to establish a regulatory testing framework that no longer relies on animal models.
\end{abstract}

Keywords: animal testing; non-animal alternatives; medical devices biological safety; toxicology; regulatory acceptance.

Resumen - Seguridad biológica de los dispositivos médicos: hacia pruebas sin animales

Los animales han sido utilizados desde hace tiempo como sujetos experimentales para apoyar el progreso científico y los avances de la medicina. A día de hoy, diversos protocolos incluyendo el uso de animales todavía están en vigor en múltiples campos científicos y aplicaciones, como por ejemplo el de la seguridad de los dispositivos médicos. El objetivo de dichos estudios es determinar si un dispositivo medico es seguro para su uso humano o si supone un riesgo para la salud del paciente. Las pruebas en animales para este 
propósito están motivadas por requisitos regulatorios, estipulando que el uso de este tipo de test es necesario y justificándolo en un contexto de gestión de riesgos. Los modelos animales ya no se usan de manera sistemática como en el pasado, pero siguen siendo una piedra angular en el proceso de toma de decisión delicado, relacionado con el marketing de los dispositivos médicos. Sin embargo, las pruebas en animales tienen limitaciones, como las preocupaciones éticas y la validez de los datos que cuestionan su uso para este fin. Una atención especial está dada a día de hoy a las alternativas libres de animales para respaldar mejor la aplicación del concepto de los 3R (replacement, reduction, refining) en este campo. Desgraciadamente, los métodos muy avanzados y tecnologías en desarrollo encuentran obstáculos importantes (p.ej. validación y estandarización) que impiden y ralentizan su implementación como alternativas aceptadas del punto de vista regulatorio. Para superar estas dificultades, el proceso de aceptación regulatoria de las alternativas se podría optimizar. Este se puede alcanzar por ejemplo mejorando la cooperación, la coordinación y la comunicación entre los diferentes actores, i.e. investigadores, organismos regulatorios certificadores e industrias. Generalmente, una atención especial se debe prestar al compromiso y a un esfuerzo común para mejorar la eficacia de este proceso, y para establecer un marco regulatorio de comprobación que no dependa más de los modelos animales

Palabras clave: pruebas en animales ; alternativas libres de animales ; seguridad biológica de dispositivos médicos ; toxicología; aceptación regulatoria.

\section{Contents}

1. Preface

2. Animals used for scientific purposes

3. Animal testing and development of medical devices

4. European Union Legal Framework of Medical Devices Biological Safety

5. Animal testing and medical devices biological evaluation (toxicological studies)

6. General limitations of animal testing and specific limitations of animal testing relevant to toxicological studies

7. Alternatives to animal testing used for toxicological studies

8. Implementation of animal testing alternatives

9. Conclusion

10.Bibliography

\section{Preface}

Significant milestones were achieved over the past within the field of medical devices. The development and safety assessment of these advances greatly relied on animal testing. Nowadays, the use of animals for such purposes is however debated in the scientific community and the society as a whole, especially since animals are recognized as sentient beings. Based on this consideration and given the broad advanced scientific knowledge currently available, the question has raised on the use of alternatives to animal models. The evaluation of the potential and the relevance of possible alternatives, the investigation of promising approaches and the establishment of implementation strategies have thus become essential in order to achieve the ultimate goal of animal-free testing.

\section{Animals used for scientific purposes}

According to the most recent official report of the European Commission (EC), almost 11.5 million animals were used for experimental and other scientific purposes in the European Union (EU) in 2011 $11^{1,2}$. Even if it can be noted that this number slightly decreased in comparison to the previous study conducted in 2008 (just above 12 million animals) ${ }^{3}$, this significant number show that animal testing is still widely used

\footnotetext{
${ }^{1}$ The next complete report on the use of animals in the Member States will be published by the European Commission in 2019 (http://ec.europa.eu/environment/chemicals/lab_animals/legal_en.htm) (Webpage accessed on 15 May 2018)

${ }^{2}$ European Commission, Seventh Report on the Statistics on the Number of Animals used for Experimental and other Scientific Purposes in the Member States of the European Union, COM(2013) 859 final

${ }^{3}$ European Commission, Sixth Report on the Statistics on the Number of Animals used for Experimental and other Scientific 
in science. As shown on Figure 1, animal testing is currently used in diverse fields such as in basic research, production and quality control, and toxicological and safety evaluation. The most commonly used animals are rodents (mice and rats for example), followed by cold blooded animals (fishes and amphibians for example), birds, rabbits and other animals (Figure 2). The following section provides information on research conducted using different animal species.

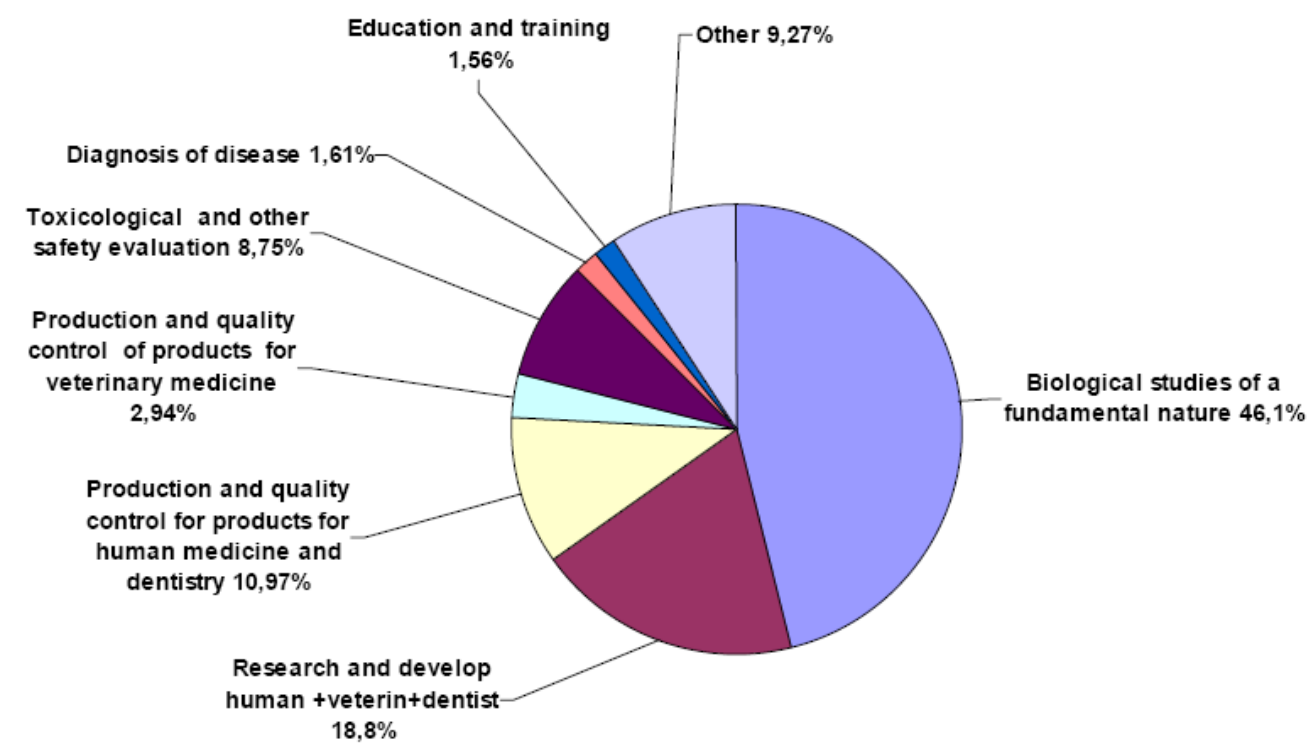

Figure 1 Purposes of experiments using animal testing in the EU Member States.

(Source: Seventh Report on the Statistics on the Number of Animals used for Experimental and other Scientific Purposes in the Member States of the European Union, report from the commission to the council and the European parliament, 2013)

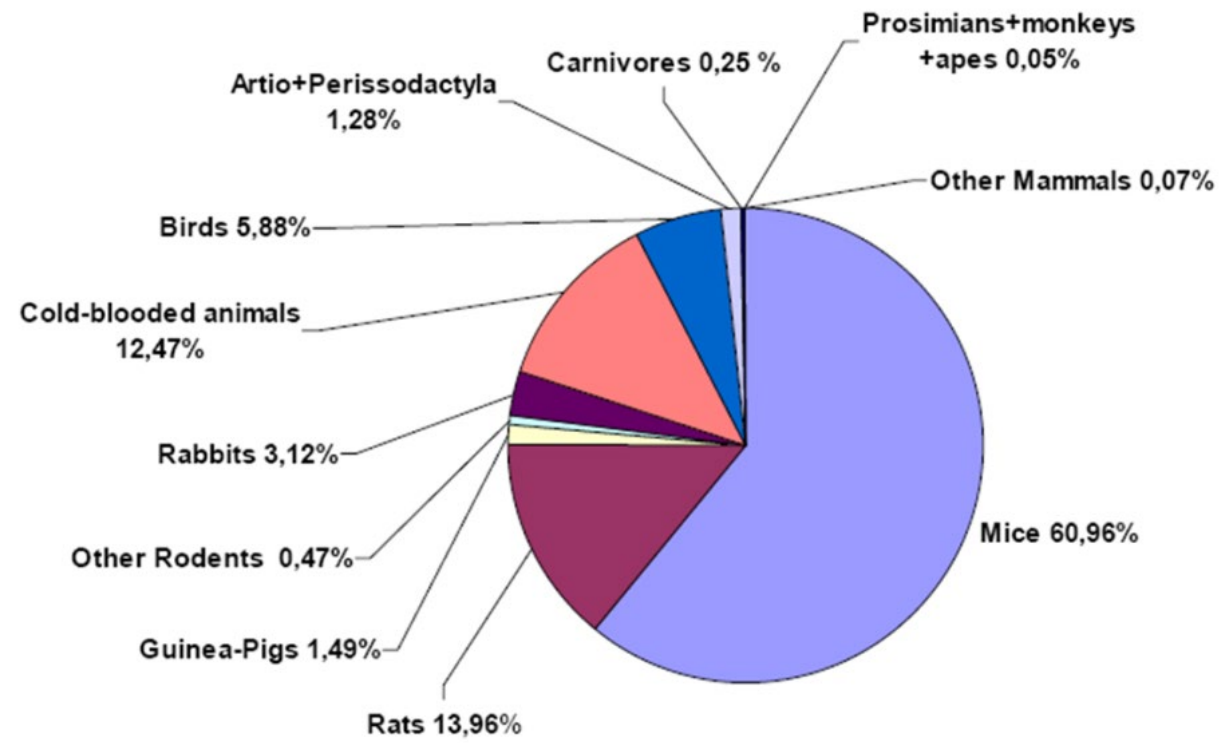

Figure 2 Percentages of animals used by classes in the EU Member States.

(Source: Seventh Report on the Statistics on the Number of Animals used for Experimental and other Scientific Purposes in the Member States of the European Union, report from the commission to the council and the European parliament, 2013)

\subsection{Rodents}

Rodents are small gnawing mammals having a pair of incisors in each of their upper and lower jaws. Mice, rats, squirrels, hamsters, guinea pigs and chinchillas for example are belonging to the rodent family. 
With a percentage of $76.88 \%$ (i.e. around 8.8 million of mice, rats, guinea pigs and other rodents) over all the animals considered for the statistical evaluation of the EC, rodents are the most used animals in laboratory research ${ }^{2}$. Their small size, ease of handling, low cost, short lifespan and good ability to breed in captivity make rodents a perfect mammal for laboratory studies. From a scientific point of view, the most significant advantage of using rodents (especially mice) is the high comparability between the mouse and the human genomes. A study performed by Mural et. al. showed for example that only 14 over 731 genes located on the mouse chromosome 16 had no counterparts on the investigated human chromosomes ${ }^{4}$. This accounts for approximately $2 \%$ difference only. Numerous other studies focused on the mouse genome to gain additional knowledge on the genome itself (gene location, identification, alteration, mutation ...) and on the understanding of its function sequences (gene transcription, replication ...) $)^{5,6}$. All those investigations performed in the last decades led to the development of well-established experimental mouse models. As a consequence, these models are nowadays used by the scientific community in a wide range of experiments.

In basic research, mice are used for example to study the physiology of small mammals. This covers the study of the cardiovascular, respiratory, digestive and renal systems as well as fundamental biological mechanisms such as regulatory systems (thermoregulation, water regulation....) ${ }^{7,8,9}$. In biomedical research, research on rodents mainly focuses on the study of human diseases. Rodents can suffer from diverse same diseases as humans do (for example diabetes), and other diseases and pathologies can be induced in mice by manipulating their genes. Gene manipulation consists in inducing the mutation, loss, under-expression or over-expression of a gene in the mouse genome, or adding a new gene to $\mathrm{it}^{10}$. Genetically engineered mice are commonly created by modifying the mouse embryonic stem cells with human DNA before injecting them into blastocyst (pre-embryonic cell structure) or by injecting a DNA sequence containing a specific gene into mouse embryo cells ${ }^{11,12}$. Genetically engineered mice are nowadays extensively used within research. They offer scientists the possibility to acquire understanding on disease processes and to work on the development of new preventive, therapeutic and curing treatments for different diseases ${ }^{13,14}$. One example of such work is the development of new drugs and their testing. Such testing is mainly used to predict human response to drugs. Rodents are thus often used to investigate the role of these drugs for a broad range of applications: anti-inflammatory drugs for Alzheimer disease ${ }^{15}$, anti-hyperglycaemic drugs for diabetes disease ${ }^{16}$, anti-hypertensive drugs for cardiovascular disease ${ }^{17}$ and others. Another example of research line for therapeutic medicine has emerged since the last two decades: the stem cell research. One of the ideas behind this research is that functional stem cells can be transplanted when original stem cells are damaged or destroyed by an injury or a disease ${ }^{18,19}$. This seems to be a promising approach but thorough studies are still required before achieving treatment implementation.

\footnotetext{
${ }^{4}$ Mural R. J. et al., A Comparison of Whole-Genome Shotgun-Derived Mouse Chromosome 16 and the Human Genome, Science (2002), Vol. 296, 1661-1671

${ }^{5}$ Georgi B. et al., From Mouse to Human: Evolutionary Genomics Analysis of Human Orthologs of Essential Genes, PLoS Genetics (2013), Vol 9(5), e1003484

${ }^{6}$ Yue F. et al., A comparative encyclopedia of DNA elements in the mouse genome, Nature (2014), Vol 515, 355-364

${ }^{7}$ Fox J. et al, The Mouse in Biomedical Research: Normative Biology, Husbandry, and Models (2006), Academic Press

${ }^{8}$ Meneton P. et al., Renal physiology of the mouse, American Journal of Physiology - Renal Physiology (2000), Vol. 278 (3), F339F351

${ }^{9}$ Hodges M. R. et al., Defects in Breathing and Thermoregulation in Mice with Near-Complete Absence of Central Serotonin Neurons, The Journal of Neuroscience (2008), Vol. 28(10), 2495-2505

${ }_{10}$ Walrath J. C. et al., Genetically Engineered Mouse Models in Cancer Research, Advances in Cancer Research (2010), Vol. 106, $113-164$

11 Kumar T. R. et al., Transgenic Mouse Technology: Principles and Methods, Methods in Molecular Biology (2009), Vol. 590, 335-362

${ }_{12}$ Physicians committee for responsible medicine, Genetically Modified Mice, PCRM.org (2014), 13187-TOX, 1-3

${ }^{13}$ Doiron B. et al., Beta Cell Formation in vivo Through Cellular Networking, Integration and Processing (CNIP) in Wild Type Adult Mice, Current Pharmaceutical Biotechnology (2016), Vol. 17, 376-388

${ }^{14}$ Vandamme T., Use of rodents as models of human diseases, Journal of Pharmacy and BioAllied Sciences (2014), Vol. 6(1): 2-9

${ }^{15}$ McGeer M. L., NSAIDs and Alzheimer disease: Epidemiological, animal model and clinical studies, Neurobiology of Aging (2007), Vol. 28, 639-647

${ }^{16}$ Moller D. E., New drug targets for type 2 diabetes and the metabolic syndrome, Nature (2001), Vol. 414, 821-827

17 Sabino B. et al., Effects of Antihypertensive Drugs on Capillary Rarefaction in Spontaneously Hypertensive Rats: Intravital Microscopy and Histologic Analysis, Journal of Cardiovascular Pharmacology (2008), Vol. 51, 402-409

${ }^{18}$ Guasch G. and Fuchs E., Mice in the world of stem cell biology, Nature Genetics (2005), Vol. 37(11), 1201-1206

${ }^{19}$ Deep A. et al., Mouse models of spinal cord injury and stem cell transplantation, Translational Research in Anatomy 1 (2015), 2- 

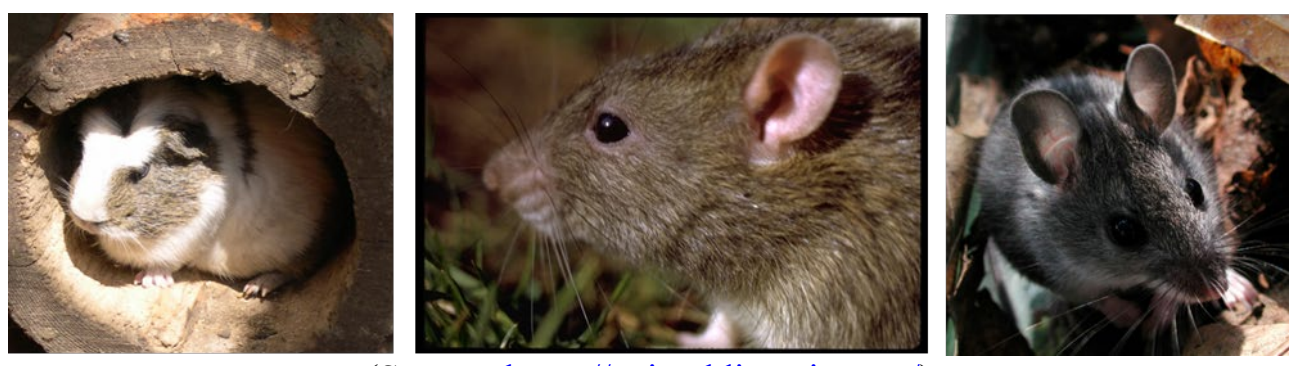

(Source: https://animaldiversity.org/)

\subsection{Cold blooded animals}

Cold blooded animals are animals which blood temperature varies with the external environmental temperature. These animals include fishes, amphibians, reptiles, insects and arachnids ${ }^{20}$. They represent $12.47 \%$ of the animals used for experimental and scientific purposes according to the EC statistical evaluation (i.e. around 1.4 million of animals) ${ }^{2}$. Cold blooded animals are the second most used animals after rodents. They are used for diverse research lines depending on their characteristics. Zebra-fishes for example have become increasingly important. This animal model has gained interest of researchers due to their ease of housing and care, fully sequenced genome, genetic similarity to humans, high fertility, fast embryonic development and transparency of the embryos ${ }^{21,22}$. Zebra-fishes are particularly used in studies aiming to assess chemical toxicity and, as for rodents, to study human diseases and genetics ${ }^{23,24}$. Another more recent interesting research line is the understanding of organ regeneration processes (cellular and molecular mechanisms) such as those related to heart regeneration for example ${ }^{25,26}$. Given the potential and perspectives of novel research studies that offer the zebra-fish model, it is expected that the significant development of models utilising this species will continue to happen in the near future ${ }^{27,28,29,30,31}$. Frogs are also used for organ regeneration research ${ }^{32}$ but they are rather used for studying biological mechanisms related to reproduction (in particular endocrinology) and embryonic development ${ }^{33,34}$. Reptiles are not extensively used for research studies but they slowly gain interest of scientists. Up to now, the research involving reptiles mainly focused on physiological studies and the unique substances they produce ${ }^{35,36}$.

\footnotetext{
${ }^{20}$ Although used for research studies (flies in genetics for example), insects and arachnids are not discussed within this section since their use is not regulated by Directive 2010/63/EU on the protection of animals used for scientific purposes and not considered within the report on the statistics on the number of animals used for experimental and other scientific purposes in the member states of the European Union.

${ }^{21}$ Lardelli M. Using zebrafish in human disease research: some advantages, disadvantages and ethical considerations, in: Proceedings of 2008 ANZCCART Conference, Auckland, New Zealand, 23-28

${ }^{22}$ Howe K. et al., The zebrafish reference genome sequence and its relationship to the human genome, Nature (2013), Vol. 496, 498-503

${ }^{23}$ Deep A. et al., Mouse models of spinal cord injury and stem cell transplantation, Translational Research in Anatomy 1 (2015), 210

${ }^{24}$ Santoriello C. et al., Hooked! Modeling human disease in zebrafish, The Journal of Clinical Investigation (2012), Vol. 122(7), 2337-2343

${ }^{25}$ WenChao S. et al., Using zebrafish as the model organism to understand organ regeneration, Science China Life Sciences (2015), Vol. 58, 343-351

${ }^{26}$ Kikuchi K., Advances in understanding the mechanism of zebrafish heart regeneration, Stem Cell Research (2014), Vol. 13, 542555

${ }^{27}$ Jen J. et al., Zebrafish models of cancer: progress and future challenges, Current Opinion in Genetics \& Development (2014), Vol. $24,38-45$

${ }^{28}$ Gutiérrez-Lovera C. et al., The Potential of Zebrafish as a Model Organism for Improving the Translation of Genetic Anticancer Nanomedicines, Genes (2017), Vol. 8(349), 1-20

${ }^{29}$ Stewart A. M. et al., Zebrafish models for translational neuroscience research: from tank to bedside, Trends in Neurosciences (2014), Vol. 37(5), 264-278

${ }^{30}$ Kalueff A. V. et al., Zebrafish as an emerging model for studying complex brain disorders, Trends in Pharmacological Sciences (2014), Vol. 35(2), 63-75

${ }^{31}$ Shen C. and Zuo Z. Zebrafish as a Model to Study Autism Spectrum Disorder Caused by Environmental Chemicals Exposure, Journal of Alzheimer's Disease \& Parkinsonism (2016), Vol. 6(6), 1000288

${ }^{32}$ Diaz Quiror J. F. et al., Spinal cord regeneration: where fish, frogs and salamanders lead the way, can we follow?, Biochemical Journal (2013), Vol. 451, 353-364

33 Wallingford J.B. et al., Convergent Extension: The Molecular Control of Polarized Cell Movement during Embryonic Development, Developmental Cell (2002), Vol. 2, 695-706

${ }^{34}$ Hayes T. B. et al., Atrazine induces complete feminization and chemical castration in male African clawed frogs (Xenopuslaevis), PNAS (2010), Vol. 107(10), 4612-4617

35 Willmore W. G. et al., Purification and properties of glutathione reductase from liver of the anoxia-tolerant turtle, Trachemysscriptaelegans, Molecular and Cellular Biochemistry (2007), Vol. 297, 139-149

${ }^{36}$ Santos B. F. et al., Interaction of viper venom serine peptidases with thrombin receptors on human platelets, FEBS Letters 477 (2000), 199-202
} 

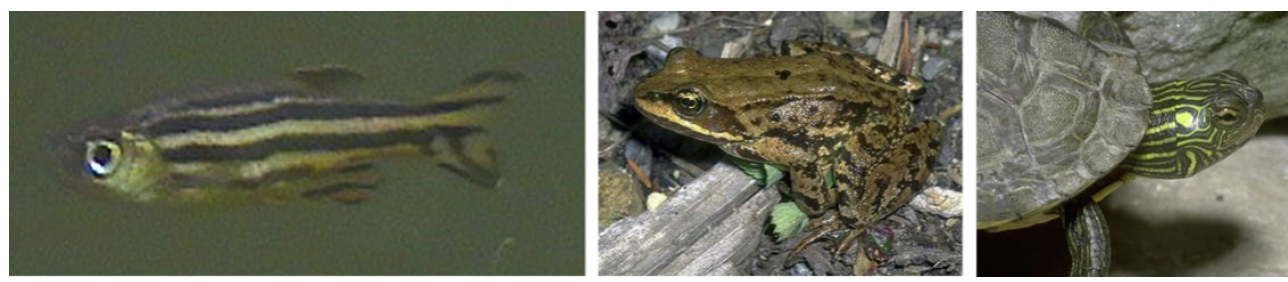

(Source: https://animaldiversity.org/)

\subsection{Birds}

Birds constitute the third most used animals in research laboratories. Approximately 680000 birds (5.88\% of the animals used) were used for experimental and scientific purposes in 2011 according to the EU statistics $^{2}$. Birds are experimental models that raised scientist interest for studying aging as they possess an outstanding resistance against aging degenerative processes. Their lifespan is up to three times as long as an average mammal of comparable size. The most common domesticated species for studying aging are the budgerigars, the canaries and the zebra finches ${ }^{37,38}$. In addition to aging, some birds are also used to study physiology, neurobiology, cognition and behaviour ${ }^{39}$. A particular attention is also currently given to chicken, especially the embryos. Chick embryos are used to test for example the response of tissue reactions to biomaterials ${ }^{40}$, to study organ development ${ }^{41}$ and to assess invasive diseases such as cancer ${ }^{42}$. Thus, the knowledge acquire so far on birds currently enables scientists to perform studies on a variety of research areas.
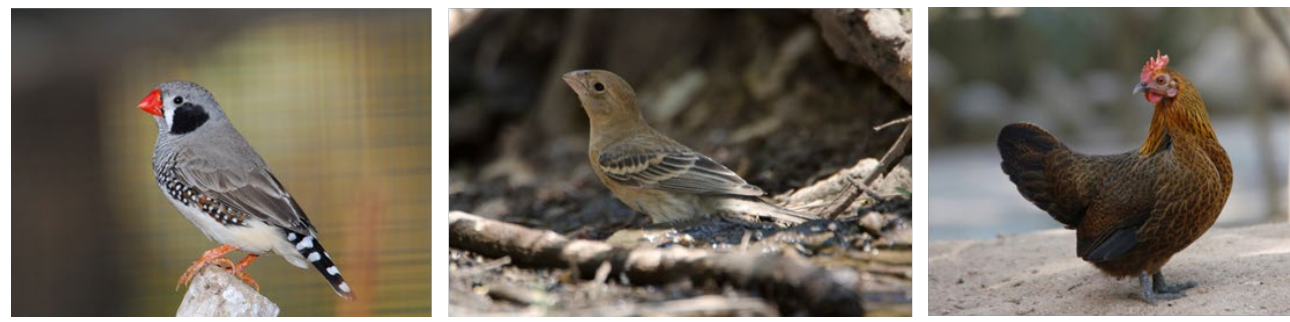

(Source: https://animaldiversity.org/)

\subsection{Mammals (other than rodents and primates)}

After rodents, rabbits are the second most popular mammal used for experimental and scientific purposes. They account for $3.12 \%$ of the animals used in the EU in 2011 (approximately 360000 rabbits) ${ }^{2}$. There are two main scientific areas that use rabbits as investigation tools: research on diseases and immunology, and safety testing. Vaccination against infectious diseases and therapeutic strategies based on rabbit antibodies to detect or treat diseases (e.g. cancer) are currently under intensive assessment ${ }^{43,44,45}$. For safety testing, rabbits are mostly subjected to procedures aiming to study skin and eye irritation after contact with medical, pharmaceutical and chemical products for example ${ }^{46}$. With a percentage of $1.28 \%$, artio- and perisso-dactyla-animals (horses, donkeys, zebras, deer, cows, sheep ...) seem to have also gained the interest of researchers. Goats and sheep for example are important for orthopaedic research. They are often used to verify that an implant is functioning as intended (i.e. mechanical function, osseo-integrative

\footnotetext{
${ }^{37}$ Holmes D. and Martin K., A Bird's-Eye View of Aging: What's in it for Ornithologists?, The Auk (2009), Vol. 126(1), 1-23

${ }^{38}$ Austad S. N., Candidate Bird Species for Use in Aging Research, ILAR Journal (2011), Vol. 52(1), 89-96

${ }^{39}$ Bateson M. and Feenders G., The Use of Passerine Bird Species in Laboratory Research: Implications of Basic Biology for Husbandry and Welfare, ILAR Journal (2010), Vol. 51(4), 395-408

${ }^{40}$ Valdes T. I. et al., The chick chorioallantoic membrane as a novel in vivo model for the testing of biomaterials, Journal of Biomedical Materials Research (2002), Vol. 62(2), 273-282

41 Vergara M.N. and Canto-Soler M. V., Rediscovering the chick embryo as a model to study retinal development, Neural Development (2012), Vol. 7(22), 1-19

${ }^{42}$ Busch C. et al., The Chick Embryo as an Experimental System for Melanoma Cell Invasion, PLOS one (2013), Vol. 8(1), e53970

${ }^{43}$ Peng X. et al., Rabbit Models for Studying Human Infectious Diseases, Comparative Medicine (2015), Vol. 65(6), 499-507

${ }^{44}$ Feng L. et al., Rabbit monoclonal antibody: potential application in cancer therapy, American Journal of Translational Research (2011), Vol. 3(3), 269-274

${ }^{45}$ Weber J. et al., From rabbit antibody repertoires to rabbit monoclonal antibodies, Experimental \& Molecular Medicine (2017), Vol. 49, e305

${ }^{46}$ Luechtefeld T. et al., Analysis of Draize Eye Irritation Testing and its Prediction by Mining Publicly Available 2008-2014 REACH Data, ALTEX (2016), Vol. 33(2), 123-134
}

96 Derecho Animal. Forum of Animal Law Studies, vol. 10/1 
function, regenerative function .... $)^{47,48,49}$. Dog is also a recognized model for this purpose since it has been shown that they have a similar bone structure as humans ${ }^{47}$. The amount of companion animals used is obviously lower than other animals due to ethical concerns but they are involved in a wide range of studies. These studies encompass the development of implant, the study of sensory systems and neuroscience, and the elaboration of new treatments for diseases ${ }^{49,50,51}$.
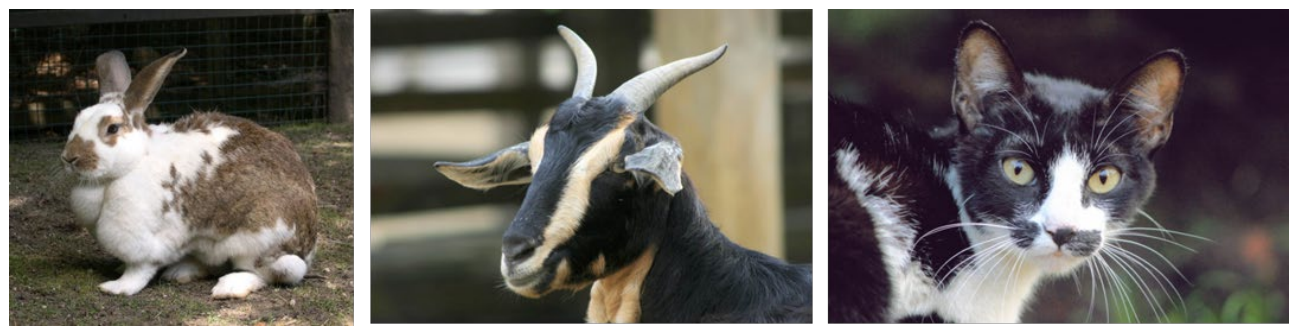

(Source: $\underline{\text { https://animaldiversity.org/) }}$

\subsection{Non-human primates}

Non-human primates are the animals the least used for research purposes in the EU. According to the report of the European Commission and the scientific committee on Health Environmental and Emerging Risks, they account for $0.05 \%$ of the animals used in 2011 and for 8898 procedures conducted in $2014^{2,52}$. The most used non-human primates are cynomolgus monkeys (7098 procedures), marmosets and tamarins (743 procedures), rhesus monkeys (612 procedures), and baboons (183 procedures). Non-human primates are mainly used in procedures aiming to develop and test the safety of pharmaceuticals and medical devices (e.g. assessment of toxicity), to prevent or treat infectious diseases (e.g. development of vaccines), to advance knowledge in neuroscience (e.g. assessment of brain structure and functions), to develop therapies for vision debilitation (e.g. testing of gene therapies strategies) and to investigate xenotransplantation (e.g. establishment of methodologies $)^{52}$. Despite their controversial use as experimental subjects, non-human primates are considered the best model to assess specific research questions due to their close genetics similarities with humans.
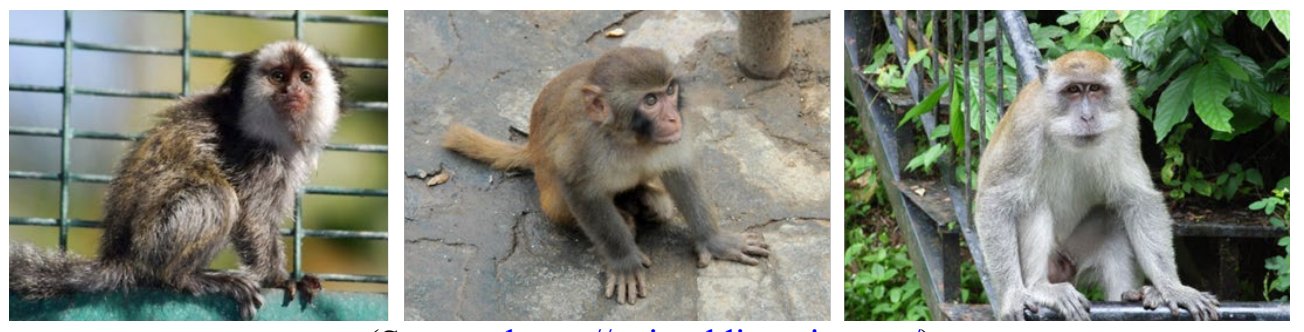

(Source: https://animaldiversity.org/)

\section{Animal testing and development of medical devices}

As described in the previous section, scientists use a significant number of animals, from different species, to conduct fundamental and applied research. Most of the studies performed are conducted toward the improvement of human health. The advances achieved in the medical field until today are considerable, and animal testing is often claimed to have significantly contributed to this success. The following section describes some of the medical advances successfully developed by means of animal testing, with a special focus on medical devices.

\footnotetext{
${ }^{47}$ Pearce A. I. et al., Animal models for implant biomaterial research in bone: a review, European Cells and Materials (2007), Vol. $13,1-10$

${ }^{48}$ Nair M. B. et al., Treatment of Goat Femur Segmental Defects with Silica-Coated Hydroxyapatite-One-Year Follow-Up, Tissue Engineering: Part A (2010), Vol. 16 (2), 385-391

${ }^{49}$ Ryugo D. K. et al., Restoration of Auditory Nerve Synapses in Cats by Cochlear Implants, Science (2005), Vol. 310, $1490-1492$

${ }^{50}$ Nagy L. J. et al., Photorefractive keratectomy in the cat eye: biological and optical outcomes, Journal of Cataract \& Refractive Surgery (2007), Vol. 33(6), 1051-1064

${ }^{51}$ Kornegay J. N. et al., Canine Models of Duchenne Muscular Dystrophy and Their Use in Therapeutic Strategies, Mammalian Genome (2012), Vol. 23(0), 85-108

52 Scientific Committee on Health Environmental and Emerging Risks, Final Opinion on 'The need for non-human primates in biomedical research, production and testing of products and devices (update 2017)' (2017)
} 


\subsection{Catheters}

Catheters are flexible tubular medical devices that, among other applications, can be introduced into vessels and cavities to deliver medications and withdraw fluids from the body (Figure 3). They are frequently used in urological, cardiovascular and gastrointestinal surgical procedures for example ${ }^{53,54}$. The history of catheter development started very long time ago with the interest for fluids and solutions transfusions ${ }^{55}$. Back that time, animal experimentation was extensively performed; mainly with dogs. Studies consisted in using needles and catheters to transfuse blood or other substances. Nevertheless, the real boom of catheter development took place in the twentieth century when invasive surgical procedures started to develop significantly. In 1844, Claude Bernard performed the first cardiac catheterization on a horse $^{54}$. This achievement was followed in 1929 by the first cardiac catheterization performed on a living person by Werner Forsmann (on his own heart) ${ }^{54}$. Such procedures required advanced catheters and since then, continuous improvements were made on those disposable devices. This is how catheters became indispensable tools in the current medicine practices.

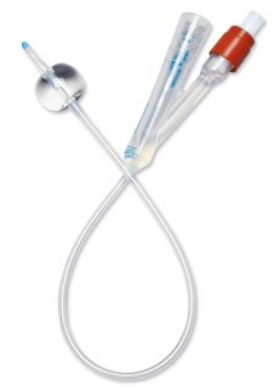

Figure 3 Example of a catheter used in urology (Foley catheter) currently on the market.

(Source: https://www.medline.com/product/Pediatric-100-Silicone-Foley-Catheters/Foley-Catheters/Z05PF148266)

\subsection{Pacemakers}

Artificial pacemakers are implantable devices that restore the heart's native electrical rhythm when the normal rhythm is impaired or stopped (Figure 4). It is able to control the cardiac activity by generating electrical impulse to the heart. This revolutionary device was initially developed after the Second World War by John Hopps as an external device ${ }^{56,57}$. His device was equipped with an external unit for cardiac activity monitoring and a bipolar catheter electrode which delivered the electrical impulse. Positive results were obtained when testing the device on dogs but it failed when testing it on humans ${ }^{58}$. The control of cardiac activity by means of a pacing device was finally achieved few years later after numerous further studies on dogs. The first implantable pacemaker, developed by William Chardack, Andrew Gage and Wilson Greatbatch, was successfully implanted in human in $1960^{57,58}$. This success marked the beginning of the pacemaker clinical use and the golden age of implantable pacemaker development.

\footnotetext{
${ }^{53}$ Feneley R. C. L. et al., Urinary catheters: history, current status, adverse events and research agenda, Journal of Medical Engineering and Technology (2015), Vol. 39(8), 459-470

${ }^{54}$ Nossaman B. D. et al., History of Right Heart Catheterization: 100 Years of Experimentation and Methodology Development, Cardiology in Review (2010), Vol. 18(2), 94-101

55 Rivera A. M. et al., The history of peripheral intravenous catheters: How little plastic tubes revolutionized medicine, ActaAnaesthesiologicaBelgica (2005), Vol. 56, 271-282

${ }^{56}$ Bains P. et al., John Hopps and the pacemaker: A history and detailed overview of devices, indications, and complications, BC Medical Journal (2017), Vol. 59(1), 29-37

${ }^{57}$ Aquilina O. A brief history of cardiac pacing, Images in Paediatric Cardiology - Journals (2006), Vol. 8(2), 17-81

${ }_{58}$ Mittal T. Pacemakers - A journey through the years, Indian Journal of Thoracic and Cardiovascular Surgery (2005), Vol. 21(3), 236-249

98 Derecho Animal. Forum of Animal Law Studies, vol. 10/1
} 


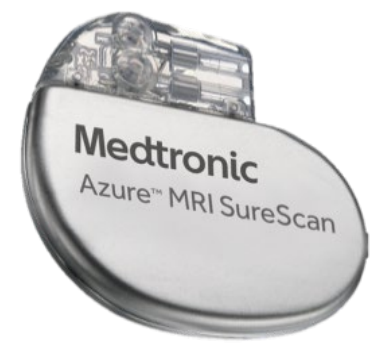

Figure 4 Example of a pacemaker currently on the market.

(Source: http://www.medtronic.com/us-en/patients/treatments-therapies/pacemakers/our.html)

\subsection{Hip prosthesis}

Hip prosthesis is an implant used in hip replacement surgeries. It is implanted when the natural hip joint is no longer able to support its function or is damaged (Figure 5). The development of hip prosthesis has started to revolutionize the orthopaedic field in the 40's/50's. At this time, several scientists (Robert Judet, Jean Judet, Frederick Röeck Thompson, Austin Moore ...) were assessing the possibility to perform hip arthroplasty ${ }^{59,60}$. The valuable studies they conducted constituted the basis of hip replacement development as driven by John Charnley between the 60's and 80 's ${ }^{61}$. As reflected by one of his famous study on the lubrication of animal joints, a great part of Charnley's work was focusing on animals ${ }^{62}$. Today, this has not changed: animal testing is still the testing of choice in orthopaedic research to assess hip prosthesis and refine replacement procedures. Animals are used for example to evaluate the biocompatibility, the safety and the effectiveness of new developed devices. To do so, a broad range of animals are used: sheep, goats, rats, mice, horses, pigs, and mostly dogs and rabbits ${ }^{47,63}$. Animal models were, and are still, considered an essential component in the establishment of what is nowadays known as the most successful orthopaedic surgery.

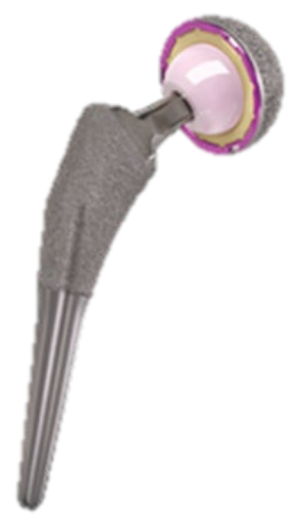

Figure 5 Example of a hip prosthesis currently on the market.

(Source: http://www.zimmerbiomet.com/medical-professionals.html)

\subsection{Dialysis machine}

Kidneys are organs that filter blood to remove toxins and extra fluids from the body by means of urine production ${ }^{64}$. Kidney failure may happen to any person and constitutes a serious problem because

\footnotetext{
${ }^{59}$ Gomez P. F. and Morcuende J. A. Early attempts at hip arthroplasty: 1700s to 1950s, Iowa Orthopaedic Journal (2005), Vol. 25, 25-29.

${ }^{60}$ Pramanik S. et al., Chronology of total hip joint replacement and materials development, Trends in Biomaterials and Artificial Organs (2005), Vol. 19(1), 15-25

${ }^{61}$ Gomez P. F. and Morcuende J. A historical and economic perspective on Sir John Charnley, Chas f. Thackray limited, and the early arthoplasty industry, The Iowa Orthopaedic Journal (2005), Vol. 25, 30-37.

${ }^{62}$ Charnley J. The lubrication of animal joints in relation to surgical reconstruction by arthroplasty, Annals of the Rheumatic Diseases (1960), Vol. 19, 10-19

63 Sumner D. R. et al., Animal models relevant to cementless joint replacement, Journal of Musculoskeletal and Neuronal Interactions (2001), Vol. 1(4), 333-345

${ }^{64}$ Botting J. H. Development of Dialysis to Treat Loss of Kidney Function, Animals and Medicine: The Contribution of Animal Experiments to the Control of Disease, Cambridge: Open Book Publishers (2015), 79-86
} 
kidneys have a vital function. The need for treating patients with kidney failure raised much earlier than the $20^{\text {th }}$ century but significant progresses were made in 1914 and $1945^{65}$. In 1913, John Abel reported in a study the possibility to perform ex vivo blood dialysis and return the blood to living animals ${ }^{65,66}$. In 1945 , Willem Kolff was the first to treat a human patient who suffered from acute renal failure ${ }^{65,67}$. The developed setup was initially referenced as 'artificial kidney' but was later named 'dialysis machine' (Figure 6). History shows that most of the experiments leading to the development of dialysis machines were performed using dogs and rabbits. Current research on dialysis machines still uses animals and focuses nowadays on improving patients' quality of life ${ }^{68}$. The replacement of lost functions of a key organ as a kidney was a substantial achievement in medicine and contributes nowadays to saving many lives around the world every day.

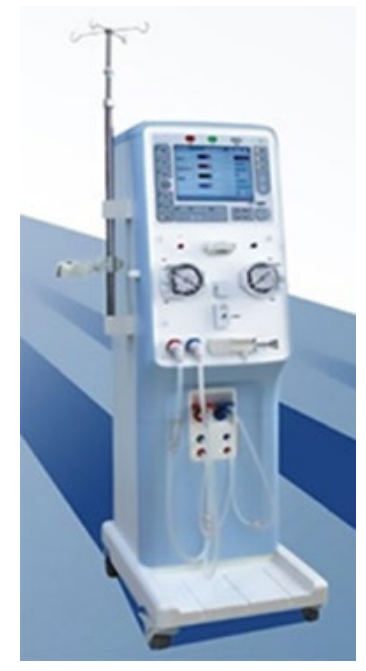

Figure 6 Example of a dialysis machine currently on the market.

(Source: http://www.dialifegroup.com/dialysis-devices.html\#dialysismachines)

\subsection{Magnetic resonance imaging device}

Magnetic resonance imaging (MRI) device is a high performance machine that enables the imaging of tissues and organs, and the study of the physiological mechanisms of the body (Figure 7). The basics concepts of this technological innovation were laid down by Raymond V. Damadian, Paul C. Lauterbur and Peter Mansfield in the 70 ' $s{ }^{69,70}$. Animal testing performed for the development of MRI relied on clam, mice, rats, rabbits and even $\operatorname{dogs}^{70,71}$. Depending on the aim of the studies, animals were used alive or dead. They were used for example to demonstrate the feasibility of tracing the flow of specific agents in the body to improve imaging contrast, and to analyse their healthy or damaged organs (e. g. infarcted heart). Since its application in the early 80's in clinical activities, MRI has turned into a very-well established imaging method and became a significant asset for biomedical investigations in humans. Given that different organs and tissues provide different contrast on a MRI scan, it is possible to visualize potential pathological processes or organ/tissue abnormalities on the image. Thus, MRI is nowadays a powerful tool in medical diagnosis and the detection of diseases such as cancer (tumor) ${ }^{72}$.

\footnotetext{
${ }^{65}$ Cameron J. S. The prehistory of haemodialysis as a treatment for uraemia, GiornaleItaliano di Nefrologia (2016), Vol. 33(S66), ISSN 1724-5590

${ }^{66}$ Abel J. et al., On the removal of diffusible substances from the circulating blood of living animals by dialysis, Journal of Pharmacology and Experimental Therapeutics January (1914), Vol. 5(3), 275-316

${ }^{67}$ Vienken J. 'Bioengineering for life': a tribute to Willem Johan Kolff, Nephrology Dialysis Transplantation (2009), Vol. 24, 22992301

${ }^{68}$ Davenport A. Portable and wearable dialysis devices for the treatment of patients with end-stage kidney failure: Wishful thinking or just over the horizon?, Pediatric Nephrology (2015), Vol. 30, 2053-2060

${ }^{69}$ Hayden M. E. and Nacher P. J. History and physical principles of MRI, Magnetic Resonance Imaging Handbook, CRC Press (2016), Chapter 1

${ }^{70}$ de Haën C. Conception of the First Magnetic Resonance Imaging Contrast Agents: A Brief History, Topics in Magnetic Resonance Imaging (2001), Vol. 12(4), 221-230

${ }^{71}$ Geva T. Magnetic Resonance Imaging: Historical Perspective, Journal of Cardiovascular Magnetic Resonance (2006), Vol. 8, 573-580

72 Choyke P. L. Functional Tumor Imaging With Dynamic Contrast-Enhanced Magnetic Resonance Imaging, Journal of magnetic resonance imaging (2003), Vol. 17, 509-520
} 


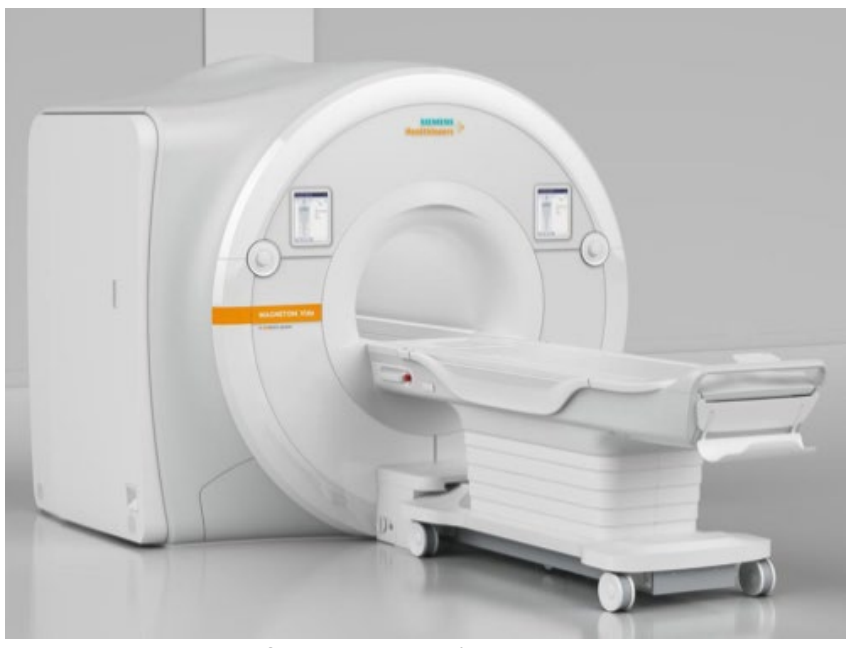

Figure 7 Example of a MRI device currently on the market.

(Source: https://www.healthcare.siemens.ch/magnetic-resonance-imaging/3t-mri-scanner)

\subsection{Cochlear implant}

A cochlear implant is used to treat patients who are suffering from deafness or severe losses in hearing ${ }^{73}$. It is a surgically implanted device that electrically stimulates the neurons of the auditory nerve by converting sound into an electrical current (Figure 8) ${ }^{74}$. The early invention of this implant started in 1957 with André Djourno and Charles Eyriès who succeeded to excite the human auditory nerve for the first time $^{73,74}$. The first cochlear implant was implanted by William House and John Doyle four years later ${ }^{73,74}$. Following this achievement, animal studies were conducted to optimize and develop the device. Cats have been used for example to explore the sound and electrical stimulations of the ear and to assess the biocompatibility of cochlear implant electrodes ${ }^{73}$. Nowadays, research studies still involve cats but other models such as ferrets, gerbils, guinea pigs and miniature pigs have also gained increasing attention in the last year ${ }^{73,75,76,77}$. These animal models are opening potential new research perspectives for the further improvement of cochlear implants ${ }^{77}$; implants which have revolutionized the field of otology by providing patients the restoration of their auditory sense.
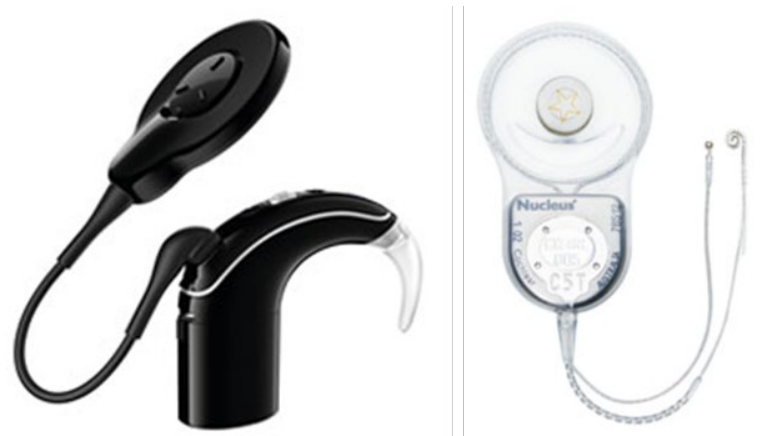

Figure 8 Example of a cochlear implant currently on the market (left: implant's external part, right: implant's internal part).

(Source:https://www.cochlear.com/us/for-professionals/products/cochlear-implants/products)

\section{European Union Legal Framework of Medical Devices Biological Safety}

\footnotetext{
${ }^{73}$ Eshraghi A. A. et al., The cochlear implant: Historical aspects and future prospects, The Anatomical Record (Hoboken) (2012), Vol. 295(11), 1967-1980

${ }^{74}$ Mudry A. and Mills M. The Early History of the Cochlear Implant, JAMA Otolaryngology - Head and Neck Surgery (2013), Vol. 139(5), 446-453

${ }^{75}$ Kretzmer E. A et al., An Animal Model for Cochlear Implants, Archives of Otolaryngology - Head and Neck Surgery (2004), Vol. 130, 499-508

${ }^{76}$ Hartley D. E. H. et al., Bilateral cochlear implantation in the ferret: A novel animal model for behavioural studies, Journal of Neuroscience Methods (2010), Vol. 190(2), 214-228

77 Yi H. et al., Miniature pigs: a large animal model of cochlear implantation, American Journal of Translational Research (2016), Vol. 8(12), 5494-5502
} 
Based on the European Union Legislation, medical devices are defined as ${ }^{78}$ :

"any instrument, apparatus, appliance, software, material or other article, whether used alone or in combination, together with any accessories, including the software intended by its manufacturer to be used specifically for diagnostic and/or therapeutic purposes and necessary for its proper application, intended by the manufacturer to be used for human beings for the purpose of:

- diagnosis, prevention, monitoring, treatment or alleviation of disease,

- diagnosis, monitoring, treatment, alleviation of or compensation for an injury or handicap,

- investigation, replacement or modification of the anatomy or of a physiological process,

- control of conception,

and which does not achieve its principal intended action in or on the human body by pharmacological, immunological or metabolic means, but which may be assisted in its function by such means".

The term 'medical devices' covers thus a wide range of products, ranging from single-use compresses to high-technology diagnostic devices such as the magnetic resonance imaging machine (see section 3 ). When developing a medical device, three main aspects have to be considered: the efficacy of the product, its quality and its safety. Those aspects must be ensured following regulatory guidance and are often linked to animal testing, in particular when assessing the product safety. The following section reviews the current status of regulatory guideline applicable to medical devices marketed in the EU and to the protection of animals used for scientific purposes.

\subsection{Council Directives applicable to medical devices}

Council directives are official guidance documents dealing with various subject matters that aim to define objectives to be reached by the EU Member States. Directives for medical devices set a regulatory framework that defines the essential requirements that medical devices shall fulfil to be marketed in the EU. Currently, three directives are in force:

- Council Directive 90/385/EEC on Active Implantable Medical Devices (AIMDD) (1990) ${ }^{79}$

- Council Directive 98/79/EC on In Vitro Diagnostic Medical Devices (IVDMD) (1998) ${ }^{80}$

- Council Directive 93/42/EEC on Medical Devices (MDD) $(1993)^{81}$

The definition of active medical devices is provided in Directive 90/385/EEC (AIMDD) as "any medical device relying for its functioning on a source of electrical energy or any source of power other than that directly generated by the human body or gravity". Active medical devices may be implanted, meaning that they can be "totally or partially introduced, surgically or medically, into the human body or by medical intervention into a natural orifice" and are "intended to remain after the procedure" ". Active implantable devices described in the introduction are for example pacemakers and some catheters.

The Directive 98/79/EC (IVDMD) covers in vitro diagnostic medical devices, i.e. "any medical device which is a reagent, reagent product, calibrator, control material, kit, instrument, apparatus, equipment, or system, whether used alone or in combination, intended by the manufacturer to be used in vitro for the examination of specimens, including blood and tissue donations, derived from the human body, solely or principally for the purpose of providing information concerning a physiological or pathological state, or concerning a congenital abnormality, or to determine the safety and compatibility with potential recipients, or to monitor therapeutic measures" ${ }^{\prime 80}$. Typical examples of such devices are reagents used in pregnancy test and kit for blood analysis.

The medical devices not covered by the two Directives described above falls under the Directive 93/42/EEC. This Directive covers the largest amount of medical devices, making this Directive the main

\footnotetext{
${ }^{78}$ European Commission, Council Directive, Directive 2007/47/EC amending Council Directive 90/385/EEC on the approximation of the laws of the Member States relating to active implantable medical devices, Council Directive 93/42/EEC concerning medical devices and Directive 98/8/EC concerning the placing of biocidal products on the market, Official Journal of the European Union (2007),

L 247/21

${ }^{79}$ European Commission, Council Directive, Directive 90/385/EEC on the approximation of the laws of the Member States relating to active implantable medical devices, Council Directive, Official Journal of the European Union (1990), 1990L0385

${ }^{80}$ European Commission, Council Directive, Directive 98/79/EC on in vitro diagnostic medical devices, Official Journal of the European Union (1998), 1998L0079

${ }^{81}$ European Commission, Council Directive, Directive 93/42/EEC concerning medical devices, Official Journal of the European Union (1993), L 169/1

102 Derecho Animal. Forum of Animal Law Studies, vol. 10/1
} 
Directive regulating medical devices. It encompasses ophthalmic devices, dental products, disposables, hospital equipment and many others. Concrete examples of such devices mentioned in the introduction are hip and cochlear implants.

Medical devices legislation has for ultimate objective to guarantee optimal patient health care and safety. The main challenge is to ensure that the technological progresses and innovations do not interfere with safety. To do so, the Directives laid down requirements with which Member States shall comply. Directive documents are 'only' guidelines, but Member States shall adopt and publish their own laws, regulations and administrative provisions in order to comply with them. Only devices complying with the relevant Directive and national rules can be approved for placement on the EU market. Directives regulate numerous aspects related to the life cycle of medical devices. It lists requirements from the device development phase to its performance within its final application. For implantable devices, incidents occurring after device implantation even have to be controlled (post market surveillance, complaint handling). Controls defined in the directives are associated to:

- Essential requirements related to the device design and construction: material intrinsic properties, materials combinations compatibility, infection and microbial contamination, protection against radiation, instruction for use, labelling.

- Conformity: quality system in place, surveillance/inspections performed by notified bodies (entities accredited to verify that products fulfil the established requirements), correct classification of the device (depending on device features and application), CE marking, clinical evaluations.

- Examination: review of the available device documentation by notified bodies and evaluation of product conformity.

- Verification procedure: Declarations of the manufacturer that products are conform to the examination, provisions to prove homogeneous production of the devices, testing of devices by the notified body to verify conformity.

The overall assessment of medical devices is based on a risk/benefit analysis. This means that the benefits of a product must outweigh the risks existing by using the device. This implies that the risks associated to the design, manufacturing and packaging of the device must be minimized or reduced to an extent that the clinical conditions and safety of the patient is not impaired. The level of health protection and safety can only be guaranteed when the remaining risks are considered acceptable. Risk management is one of the essential tasks conducted by medical device suppliers to deliver the best innovative technologies and safest products.

\subsection{ISO standard applicable to medical devices biological evaluation}

One of the key concepts of medical device safety is the demonstration of the device biocompatibility. Biocompatibility is the "ability of a material to perform with an appropriate host response in a specific application" 82 . In other words, biocompatibility testing aims to protect patients from potential biological hazards (bacteria, viruses, bio-toxins ...), chemicals or fragments particles for example that could harm their health.

To assess biocompatibility of medical devices, a biological evaluation consisting of a comprehensive set of tests is conducted. This evaluation is regulated by a series of standards very well-known in the medical device field and published by the International Organization for Standardization: the ISO 10993. This standard has for objective to provide guideline for the characterization of medical devices in order to evaluate their biological safety. It does not specify pass/fail criteria nor defines a rigid set of tests. Manufacturers are responsible for the selection of tests they deem relevant for each device depending on the intended device application. As described in the previous section, a risk management process is required by Council Directives and the evaluation of biological safety form part of this procedure ${ }^{83}$. Biological safety assessment is thus an essential evaluation that must be performed. Table 1 reports the different topics covered by ISO 10993. Among the eighteen parts, five of them involve animal testing. Animal tests are performed to assess: skin irritation and intra-cutaneous reactivity (Part 10) ${ }^{84}$, skin sensitization (Part 10) ${ }^{84}$,

\footnotetext{
${ }^{82}$ Morais J. M. et al., Biomaterials/Tissue Interactions: Possible Solutions to Overcome Foreign Body Response, American Association of Pharmaceutical Scientists Journal (2010), Vol. 12(2), 188-196

${ }^{83}$ ISO 10993-1, Biological evaluation of medical devices - Part 1: Evaluation and testing within a risk management process, International Organization for Standardization (2009)

${ }^{84}$ ISO 10993-10, Biological evaluation of medical devices - Part 10: Tests for irritation and skin sensitization, International Organization for Standardization (2010)
} 
systemic toxicity (Part 11) ${ }^{85}$, genotoxicity, carcinogenicity and reproductive toxicity (Part 3$)^{86}$, implantation $\left(\right.$ Part 6) ${ }^{87}$ and haemocompatibility (Part 4) ${ }^{88}$. A detail description of these tests is provided in section 5 below.

Table 1 Standard ISO 10993 (Biological evaluation of medical devices (Highlighted in grey: standards implying animal testing)

\begin{tabular}{|l|l|}
\hline ISO 10993-1 & Part 1: Evaluation and testing within a risk management process \\
\hline ISO 10993-2 & Part 2: Animal welfare requirements \\
\hline ISO 10993-3 & Part 3: Tests for genotoxicity, carcinogenicity and reproductive toxicity \\
\hline ISO 10993-4 & Part 4: Selection of tests for interactions with blood \\
\hline ISO 10993-5 & Part 5: Tests for in vitro cytotoxicity \\
\hline ISO 10993-6 & Part 6: Tests for local effects after implantation \\
\hline ISO 10993-7 & Part 7: Ethylene oxide sterilization residuals \\
\hline ISO 10993-8 & Withdrawn \\
\hline ISO 10993-9 & $\begin{array}{l}\text { Part 9: Framework for identification and quantification of potential degradation } \\
\text { products }\end{array}$ \\
\hline ISO 10993-10 & Part 10: Tests for irritation and skin sensitization \\
\hline ISO 10993-11 & Part 11: Tests for systemic toxicity \\
\hline ISO 10993-12 & Part 12: Sample preparation and reference materials \\
\hline ISO 10993-13 & $\begin{array}{l}\text { Part 13: Identification and quantification of degradation products from polymeric } \\
\text { medical devices }\end{array}$ \\
\hline ISO 10993-14 & Part 14: Identification and quantification of degradation products from ceramics \\
\hline ISO 10993-15 & $\begin{array}{l}\text { Part 15: Identification and quantification of degradation products from metals and } \\
\text { alloys }\end{array}$ \\
\hline ISO 10993-16 & Part 16: Toxicokinetic study design for degradation products and leachables \\
\hline ISO 10993-17 & Part 17: Establishment of allowable limits for leachable substances \\
\hline ISO 10993-18 & Part 18: Chemical characterization of materials \\
\hline
\end{tabular}

\subsection{Council Directive on the protection of animals used for scientific purposes}

The use of animals for scientific purposes such as for the tests involved in the biological evaluation of medical devices is regulated in the EU by the Directive 2010/63/EU ${ }^{89}$. This Directive has two main objectives. First, it aims to harmonise the legislation related to animal research throughout the EU Member States and, second, to regulate the use of research animals and improve their protection. This Directive applies to live non-human vertebrate animals and cephalopods, and is based on three internationally recognized principles: replacement, reduction and refinement (also known as the 3Rs Principle). This principle was initially defined in 1959 by W. M. S. Russell and R.L. Burchas ${ }^{90}$ :

- Replacement: "the substitution for conscious living higher animals of insentient material"; in the sense that conscious vertebrates could be replaced by plants, microorganisms or endo-parasites ${ }^{91}$ for

\footnotetext{
85 ISO 10993-11, Biological evaluation of medical devices - Part 11: Tests for systemic toxicity, International Organization for Standardization (2017)

${ }^{86}$ ISO 10993-3, Biological evaluation of medical devices - Part 3: Tests for genotoxicity, carcinogenicity and reproductive toxicity, International Organization for Standardization (2009)

87 ISO 10993-6, Biological evaluation of medical devices - Part 6: Tests for local effects after implantation, International Organization for Standardization (2016)

${ }^{88}$ ISO 10993-4, Biological evaluation of medical devices - Part 4: Selection of tests for interactions with blood, International Organization for Standardization (2017)

${ }^{89}$ European Commission, Council Directive, Directive 2010/63/EU on the protection of animals used for scientific purposes, Official Journal of the European Union (2010), L 276/33

90 Tannenbaum J. and Taylor Bennett B. Russell and Burch's 3Rs Then and Now: The Need for Clarity in Definition and Purpose, Journal of the American Association for Laboratory Animal Science (2015), Vol. 54(2), 120-132

${ }^{91}$ At this time, the nervous and sensory systems of endo-parasites were considered atrophied 
example. In other words, Russell and Burch considered that sentient animals could be replaced by non-sentient materials, being animals or non-animals.

- Reduction: "reduction in the numbers of animals used to obtain information of a given amount and precision"; meaning that the number of animals is reduced while valid scientific data can still be acquired.

- Refinement: "any decrease in the incidence or severity of inhumane procedures applied to those animals which still have to be used"; meaning that practices are adjusted to reduce the potential suffering, pain and distress caused to animals.

Nowadays, the 3Rs Principle is reflected and formulated in the Article 4 of the Council Directive as follow ${ }^{89}$ :

"Member States shall ensure that, wherever possible, a scientifically satisfactory method or testing strategy, not entailing the use of live animals, shall be used instead of a procedure.

Member States shall ensure that the number of animals used in projects is reduced to a minimum without compromising the objectives of the project.

Member States shall ensure refinement of breeding, accommodation and care, and of methods used in procedures, eliminating or reducing to the minimum any possible pain, suffering, distress or lasting harm to the animals"

Following these principles, essential requirements were laid down. These requirements cover a broad range of aspects:

- The use of certain animals in scientific procedures: provisions on endangered species, non-human primates, stray and feral animals from domestic species, animals from the wild, and animals bred for use in procedures.

- The scientific procedures used: anaesthesia, reuse, classification of severity of procedure, end of procedure, killing methods...

- The authorisations required to perform a procedure: competent professionals (breeders, suppliers, veterinarians...), adequate installations and equipment availability of animal records...

- The project: application for project, evaluation of project, granting of project...

- The potential use of alternatives methods to animal models: acceptance of data from other Members States to avoid duplication, relevance and suitability of alternative approaches, establishment of national committees for the protection of animals...

The legislative framework of Council Directive 2010/63/EU provides thus best practice guidance for individuals involved in animal testing. ISO 10993 (Part 2: animal welfare requirements) ${ }^{92}$ is closely related to this Directive since the animal tests described in ISO 10993 enter the scope of this Directive.

\section{Animal testing and medical devices biological evaluation (toxicological studies)}

Animal testing for the biological evaluation of medical devices is mostly used to assess the toxicological potential of devices, i.e. the adverse events they may cause to organisms ${ }^{93}$. Of course, raw materials selected to design the devices are chosen based on their non-toxicity. Nevertheless, material properties may be altered by the device manufacturing process. The addition of a colorant, the use of a thermal treatment or the sterilization of the device for example may induce the formation of toxic substances which may be released from the device along its application. For this reason, the toxicity of the devices must, in any case, be evaluated. This does not mean that animal testing will be systematically conducted. As described above, the evaluation is based on a risk assessment procedure ${ }^{94}$. If enough data are already available (clinical data and equivalence to an existing device for example) to perform the toxicological assessment and ensure that the device will not harm the patient health, animal testing may not be needed. On the contrary, if data are insufficient, animal testing may be performed. The nature and extent of the testing is then determined depending on the device final use (type and duration of contact with the body) ${ }^{95}$. The

\footnotetext{
92 ISO 10993-2, Biological evaluation of medical devices - Part 2: Animal welfare requirements, Official Journal of the European Union (2006)

${ }^{93}$ Parasuraman S. Toxicological Screening, Journal of Pharmacology and Pharmacotherapeutics (2011), Vol. 2(2), 74-79

${ }^{94}$ Myers D. K. et al., From In Vivo to In Vitro: The Medical Device Testing Paradigm Shift, ALTEX (2017), Vol. 34(4), 479-500

${ }^{95}$ Schuh J. C. L. Medical Device Regulations and Testing for Toxicologic Pathologists, Toxicologic Pathology (2008), Vol. 36, 63-
} 
following section reviews the animal testing listed in ISO 10993 that may be conducted to evaluate the biological safety of medical devices.

\subsection{Skin irritation and intra-cutaneous reactivity}

Skin irritation test is a test performed to evaluate the potential of a material to induce reversible skin damages in an animal model, i.e. an inflammatory response caused by the immune system of the skin after being in contact with a substance. Albino rabbits are the standard experimental subjects for this test ${ }^{84,96}$. This test consists in shaving the back of the rabbits and applying to their skin a test substance. The test substance may be a liquid, a solid or an extract in the case of some medical devices (extraction in polar solvent such as water, saline solution and cell culture medium, or non-polar solvent such as cottonseed oil, olive oil, sesame oil). Gauze patches, preliminary soaked in the test substance, are placed on defined dorsal sites of the rabbits (Figure 9). Control patches (commonly saturated with the liquid used for extraction) are also applied on the rabbits back in order to be able to distinguish, at the end of the assay, between the effect of the extract vehicle and the one of the material itself. The patches are maintained on the rabbits back for at least $4 \mathrm{~h}$. After this time, the patches are removed. The sites of application are then marked with permanent ink and finally washed with water. The skin reaction is evaluated by visual observation after approximately $1,24,48$ and $72 \mathrm{~h}$ for a single-exposure test. In the case of a repeated-exposure test, the skin reaction is recorded after $1 \mathrm{~h}$ removal of the patches and new patches are immediately deposited on the same locations of the previous patches. After the last exposure, the visual inspections are made at the same duration intervals as for the single-exposure test. Skin reaction is evaluated by the observation of signs of erythema and oedema and is scored depending on the severity and reversibility of the irritation. The grading of the irritation reaction is provided in ISO $10993-10^{84}$ and enables the calculation of a so called primary or cumulative irritation index (single-exposure test and repeated-exposure test respectively). This index is ultimately used to determine the classification of the test substance as negligible, slight, moderate or severe irritant.

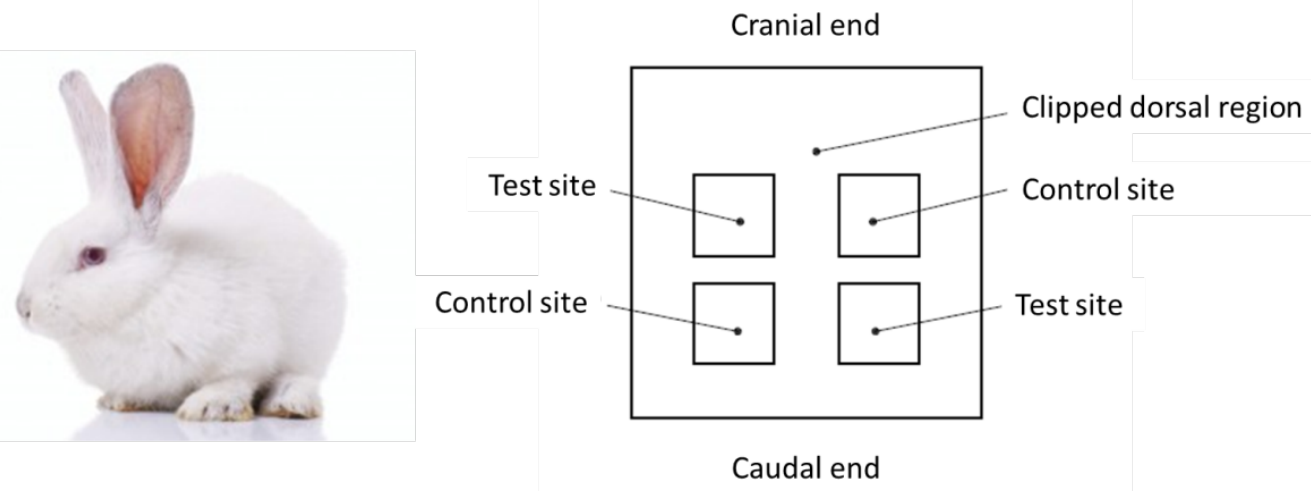

Figure 9 Location of the test/control patches sites applied on a rabbit back for skin irritation test.

(Sources: picture of the rabbit: https://blogs.rspca.org.uk/insights/2012/04/03/lab-animal-lawgovernment-actions-will-speak-louder-than-words/\#.WuQnaX9CSUk; scheme: adapted from ISO 10993-

Intra-cutaneous reactivity test is also a test aiming to assess the irritation potential of a medical device but, unlike the skin irritation test described above, the test substance is injected intra-dermally ${ }^{84}$. Since the test substance is directly placed into the skin and not simply contacting it, this test is considered much more aggressive. This test is used for implant medical devices and is often performed with extracts of the medical devices ${ }^{97}$. The basic principles of this test are quite similar to the ones of the skin irritation test: the rabbit back is shaved, the test substance is applied (in this case, five injections of control and test substance (Figure 10)), the reactivity of the skin is observed by visual observation, and the irritation grade is determined. As for the skin irritation test, the skin reaction is also examined based on signs of erythema and oedema and is scored depending on the severity and reversibility of the irritation. Medical devices are not considered irritant as long as the final scoring is 1.0 or less.

${ }^{96}$ Lee M. et al., Alternatives to In Vivo Draize Rabbit Eye and Skin Irritation Tests with a Focus on 3D Reconstructed Human Cornea-Like Epithelium and Epidermis Models, Toxicological Research (2017), Vol. 33(3), 191-203

97 Simeonova R. and Danchev N. Assessment of surgical sutures Polymed ${ }^{\circledR}$ by intracutaneous irritation test in rabbits, Interdisciplinary Toxicology (2013), Vol. 6(2), 99-102

106 Derecho Animal. Forum of Animal Law Studies, vol. 10/1 


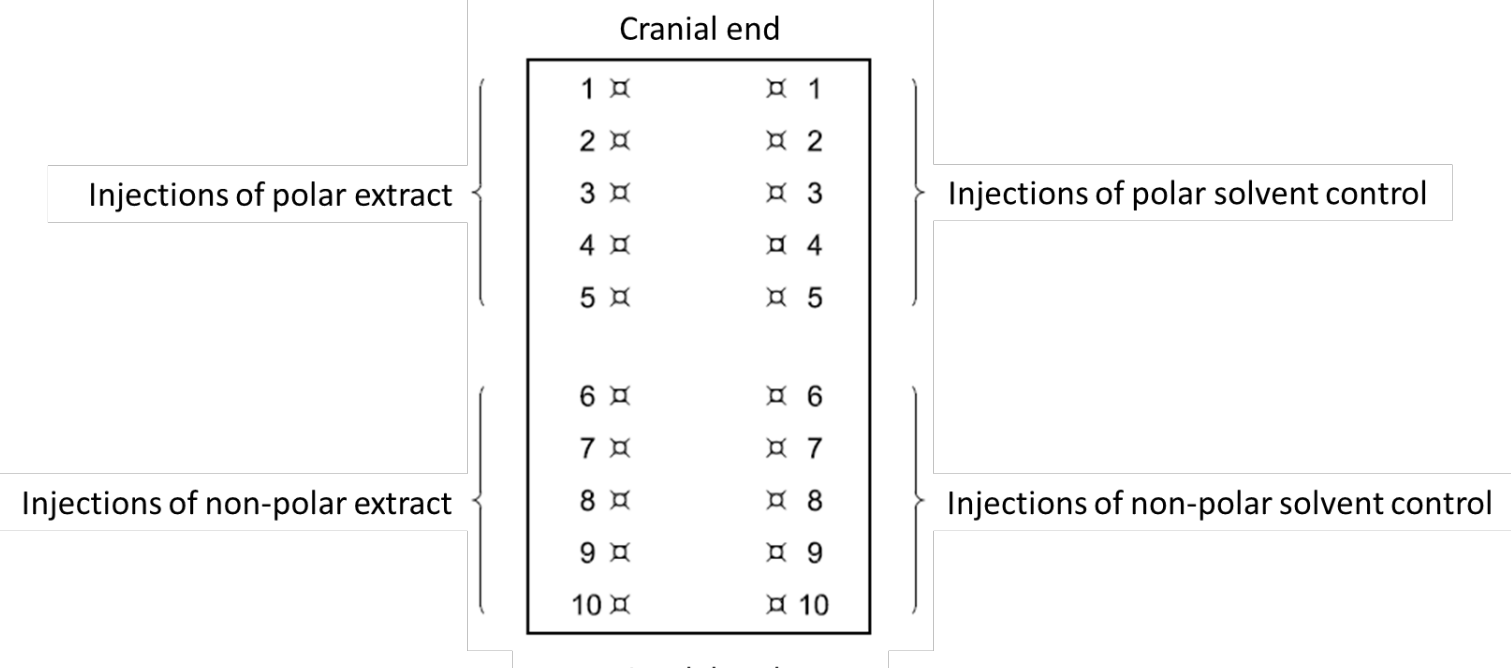

Caudal end

Figure 10 Location of the test/control injection sites applied on a rabbit back for intra-cutaneous reactivity test.

(Sources: adapted from ISO 10993-10)

\subsection{Skin sensitization}

Skin sensitization test is a test conducted to evaluate the presence of an allergen in a test substance. Foreign agents such as allergens that come into contact with skin may cause a hypersensitivity reaction due to the biological response of the body's immune system ${ }^{98}$. It is usually characterized by redness and swelling of the allergen-contacted skin. Three tests may be used to evaluate skin sensitization ${ }^{84}$ :

- The closed-patch test; using guinea pigs(referred as Buehler test)

- The maximization test; using guinea pigs (referred as GPMT)

- The local lymph node assay; using mice (referred as LLNA)

Sensitization develops in two phases. First, when skin is exposed by contact to an allergen, a specialized primary immune response is provoked ${ }^{98}$. This phase, called the induction phase, primes and sensitizes the immune system and usually does not induce clinical symptoms. The second phase, named challenge phase, is depicted as the triggering of the allergic response after re-exposure to the allergen and is associated to the development of clinical symptoms (i.e. skin reaction). It is thus necessary to first sensitise and then challenge the immune system of the animals in the Buehler test ${ }^{84.99}$. To do so, the back of the guinea pigs are shaved and patches saturated with the test substance (or liquid of the extracts for the control guinea pigs) are placed on the shaved area. The patches are removed after $6 \mathrm{~h}$. This procedure is performed three days a week during three weeks. After $14 \mathrm{~d}$, the sensitised animals can be challenged. A skin area which was not tested yet (commonly the flank) is shaved and test substance-soaked patches are applied to this area. As for the induction phase, the patches are removed after $6 \mathrm{~h}$. The guinea pigs are shaved again after $24 \mathrm{~h}$ following the last challenge phase, and $2 \mathrm{~h}$ after the shaving, the visual observation is made. The grading of the skin reaction is assigned based on the Magnusson and Kligman scale provided in ISO 10993$10^{84}$. The grading is evaluated again after $24 \mathrm{~h}$ after the first observation. The test substance is considered sensitizer if the grade of the test animals exceed the most severe reaction of the control animals.

The guinea pig maximization test (GPMT) is considered more sensitive than the Buehler test ${ }^{99}$. The GPMT relies also on an induction phase and a challenge phase ${ }^{84,99}$. Nevertheless, while the induction phase of the Buehler test implies only one step (induction by topical application), the induction phase in the GPMT implies induction by intradermal injections and topical application. The substances injected are: Freund's complete adjuvant mixed with the liquid used for the extract, the extract, and Freund's complete adjuvant mixed with the extract. Freund's complete adjuvant is used to enhance the immune reaction of the guinea pig. In the case of control animals, a blank is used instead of the test substance. The intradermal injections are performed in the previously shaved nuchal area of the guinea pigs. Figure 11 shows the distributions of

\footnotetext{
${ }^{98}$ Kimber I. et al., Skin sensitization testing in potency and risk assessment, Toxicological Sciences (2001), Vol. 59, 198-208

${ }^{99}$ Frankild S. et al., Comparison of the Sensitivities of the Buehler Test and the Guinea Pig Maximization Test for Predictive Testing of Contact Allergy, ActaDermato-Venereologica (2000), Vol. 80, 256-262
} 
the injections. After $7 \mathrm{~d}$, the injection sites are covered by a patch saturated with the test substance. The patch is removed after $48 \mathrm{~h}$. Challenge phase takes place after $14 \mathrm{~d}$ following the end of the induction phase. Skin areas which were not tested yet (commonly the flank) are shaved and patches soaked either in test substance or blank patches are applied to these areas. The patches are removed after $24 \mathrm{~h}$, and grading of the skin reaction and possible classification of test substance as sensitizer are determined as for the Buehler test.

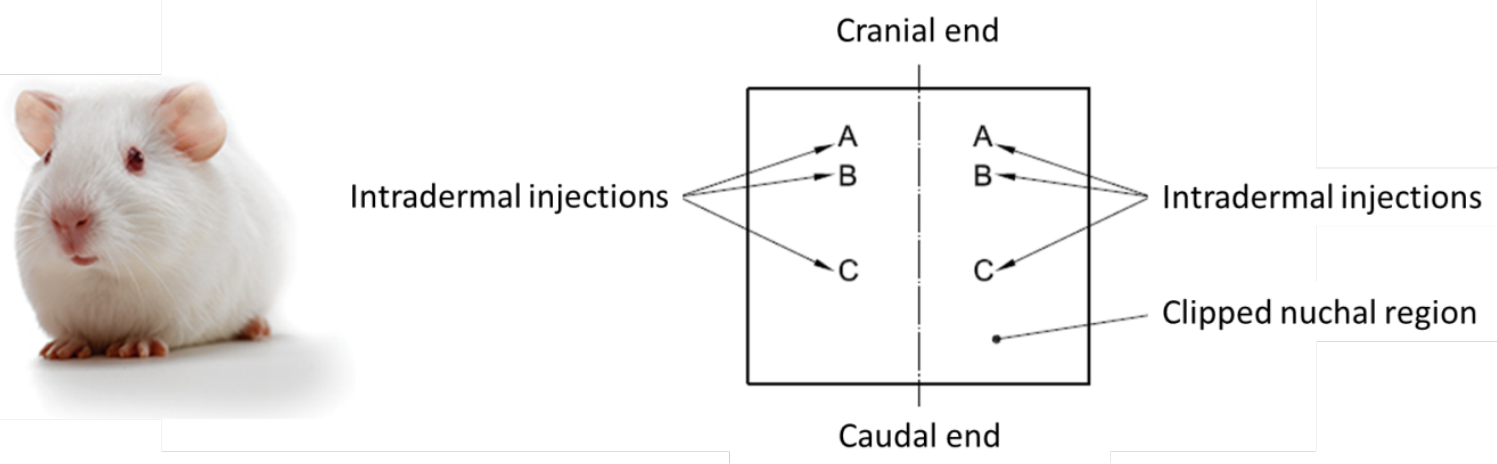

A: Freund's complete adjuvant mixed with the liquid used for the extract B: the extract or blank

C: Freund's complete adjuvant mixed with the extract or blank

\section{Figure 11 Location of the intradermal injection sites on a guinea pig nape for GMPT skin} sensitization.

(Sources: picture of the guinea pig: https://www.criver.com/products-services/find-model/hartley-guineapig?region=27; scheme: adapted from ISO 10993-10)

The local lymph node assay (LLNA) is nowadays the preferred test to evaluate skin sensitization. A characteristic of skin sensitization response during the induction phase is the proliferation of allergenresponsive lymphocytes in the draining lymph nodes of the allergen-contacted tissue ${ }^{98}$. The quantification of the lymphocytes is thus a direct approach to evaluate the degree of allergenic reaction ${ }^{100}$. The test substance (or blank for control) is applied to the dorsum of the mice ears. A fluorescent or radioactive marker is administered intravenously through the mice tails after $72 \mathrm{~h}$ following the last application. This marker enables the labelling of the proliferating lymphocytes in the lymph nodes. Five hours after this injection, the mice are euthanized and their auricular nodes are removed. Cells from the nodes are obtained by pressing the lymph nodes through a mesh and are suspended in a solvent that is either supplemented with a scintillation fluid to measure the fluorescence or directly transferred to a gamma counter to measure radioactivity. The levels of fluorescence or radioactivity related to the test substance and the blank are used to calculate the so-called Stimulation Index. To be defined as sensitizer, the substance must lead to a stimulation index equal or superior to three.

\subsection{Systemic toxicity}

Systemic toxicity is defined in ISO 10993-11 as the "toxicity that is not limited to adverse effects at the site of contact between the body and the device" ${ }^{\prime 85}$. Systemic toxicity is sub-classified in four types of toxicity: acute, subacute, subchronic and chronic. Acute toxicity usually deals with the adverse reactions that occur rapidly (typically within three days) after a single or limited exposure to a substance for $24 \mathrm{~h}$. Subacute, subchronic or chronic toxicity is rather related to the adverse reactions from repeated or continuous exposure for prolonged timeframes (subacute: exposure between $24 \mathrm{~h}$ and 28d, subchronic: exposure for a part of the lifespan, chronic: for a major part of the lifespan). There is no preferred animal species to assess systemic toxicity. Mice, rats, rabbits, dogs or monkeys for example may be used for this testing. However, the choice of the animal species may be directed by different factors such as the administration route of the test substance during the study and the duration of the study (evaluation of acute, subacute, subchronic or chronic toxicity). When investigating systemic toxicity, the test substance is administrated through dermal, intradermal, intramuscular, intravenous, oral, subcutaneous, implantation, inhalation or intraperitoneal routes. The administration must simulate, if possible, the clinical use of the investigated medical device. After the administration(s), the animals are regularly observed at a frequency

100 Montelieus J. et al., Murine local lymph node assay for predictive testing of allergenicity: two irritants caused significant proliferation, ActaDermato-Venereologica (1998), Vol. 78, 433-437

108 Derecho Animal. Forum of Animal Law Studies, vol. 10/1 
that is defined depending on the study (e.g. nature, severity, rate of onset of toxic reactions). Clinical observations such as respiratory deficiencies, eye lacrimation, excessive salivation or diarrhoea, as well as body weight changes and cases of morbidity and mortality are recorded. If relevant, clinical pathology (haematology, clinical biochemical analysis, urinalysis ...) may be also monitored along the study. After euthanasia, the gross necropsy (examination of orifices, cavities and their content) of the animals may be additionally assessed and followed by the weighing of some selected organs and histopathological studies. Results obtained are evaluated statistically based on the observations and findings made along the study (type of lesions, number of animal suffering from each lesion, mortality, behavioural abnormalities .... ${ }^{101,102}$. Finally, the adverse effects observed are discussed in terms of biological relevance and relevance to human beings.

\subsection{Genotoxicity, carcinogenicity and reproductive toxicity}

A genotoxic substance is a substance that induces gene, DNA and/or chromosome structure damages. The genotoxicity of a substance is first investigated by performing a set of in vitro studies. Bacteria are used to assess gene mutations, mammalian cells to assess chromosomal damages and mouse lymphoma cells to assess the development of cell colonies. In vivo testing may be conducted only if justified, i.e. for example when other relevant factors to genotoxicity are not covered by the in vitro testing. In vivo tests suggested by ISO 10993-3 ${ }^{86}$ all involve rodents: the mammalian in vivo micronucleus test, the chromosome aberrations test and the transgenic mutagenicity test (guidelines OECD 474, 475 and 488 respectively) $)^{103,104,105}$. The animals used for testing are exposed to the test substance and then euthanized to investigate different characteristics. The first test consists in the analysis of red blood cells of treated animals and the presence of micronuclei in those cells. The second test is based on the analysis of the metaphase (a stage of cell mitosis) of bone marrow cells and the evaluation of chromosome structure and morphology (addition of genetic material, deletion of a part of a chromosome, loss of one chromosome arm ...). The third test relies on the measurement of mutations (mutant frequency) in a specific gene. All these results are indicators of genome damages that may have been induced by the test substance.

A carcinogenic substance is a substance that induces cancer. Cancers are characterized by the uncontrolled multiplication of abnormal cells. They may form clusters (malignant tumours), invade nearby tissues and spread to other tissues by means of the bloodstream and lymphatic system. Carcinogenicity test may not be conducted if the test substance is not defined as genotoxic or is not structurally related to carcinogens for example. If testing is deemed necessary, carcinogenicity must be evaluated using rodents (usually rats) and following the guidelines OECD 451 and $453^{86,106,107}$. Similarly to systemic toxicity studies, after exposure to the test substance, animal body weight and clinical observations must be recorded. Haematology, clinical biochemical analysis and urinalysis may be also of relevance for carcinogenicity studies. After euthanasia, a gross necropsy is performed and tissues and organs are used for histopathological examination. The results are analysed in terms of tumour incidence (compared to control animals), analysis (benign or malignant tumour) and invasiveness (affected surrounding tissues, metastasis).

A reproductive toxic substance is a substance that alters the reproductive system. Such substances can for example negatively impact fertility, hormonal cycle, embryo development and intellectual development. The assessment of reproductive toxicity is conducted only if the substance may pose a concrete risk for reproduction. If the testing is judged required, testing must be conducted following guideline OECD $421^{86,108}$. This testing is performed with male and female rats. It consists in exposing the animals to the test substance (often by oral administration) and evaluating various aspects of the processes driving reproduction. As for the other toxicity studies, the body weight changes and clinical observations are

\footnotetext{
${ }^{101}$ Kang B.-C. et al., Biocompatibility and long-term toxicity of InnoPol implant - a biodegradable scaffold, Experimental Animals (2005), Vol. 54(1), 37-52

102 Wirnitzer U. et al., Systemic toxicity of di-2-ethylhexyl terephthalate (DEHT) in rodents following four weeks of intravenous exposure, Toxicology Letters 205 (2011), 8-14

${ }^{103}$ OECD (Organisation for Economic Co-operation and Development), Test No. 474: Mammalian Erythrocyte Micronucleus Test (1997)

104 OECD (Organisation for Economic Co-operation and Development), Test No. 475: Mammalian Bone Marrow Chromosome Aberration Test (1997)

${ }^{105}$ OECD (Organisation for Economic Co-operation and Development), Test No. 488: Transgenic Rodent Somatic and Germ Cell Gene Mutation Assays (2011)

${ }^{106}$ OECD (Organisation for Economic Co-operation and Development), Test No. 451: Carcinogenicity Studies (2009)

${ }^{107}$ OECD (Organisation for Economic Co-operation and Development), Test No. 453: Combined Chronic Toxicity/Carcinogenicity Studies (2009)

108 OECD (Organisation for Economic Co-operation and Development), Test No. 421: Reproduction/Developmental Toxicity Screening Test (2015)
} 
recorded. However, specific parameters are additionally assessed: oestrous cycle monitoring, thyroid hormone measurement, offspring parameters observation. Gross necropsy and histopathology are also part of the analysis. The observations and findings obtained from the study enables the preliminary evaluation of the reproductive toxicity potency of the test substance. If further data are required, specific tests may be performed in accordance with guidelines OECD 414, 415 and $416^{109,110,111}$. These tests describe the prenatal development toxicity study, and one-generation and two-generation reproduction toxicity studies. Reproductive toxicity studies cover thus the overall mechanisms implied in reproduction, from fertility to postnatal development, including parturition and lactation.

\subsection{Implantation}

Implantation is performed to evaluate the interaction between a material and a tissue by analysing the biological response of the host tissue and the retrieved material. Depending on the duration of the planned study (in accordance with the clinical exposure of the medical device), different animal models may be used. For short-term implantation, rodents and rabbits are recommended. For long-term implantation, rodents and rabbits may be used as well but dogs, sheep, goats, and pigs are usually preferred. The implantation site is defined based on the clinical use of the medical device. ISO 10993-6 describes procedures for implantation in subcutaneous tissue, in muscle, in bone and in brain tissue ${ }^{87}$. As example, a permanent hip implant might rather be tested in the hip of a goat (implantation in bone), while a fast-degrading wound dressing patch might rather be implanted subcutaneously in a rat. The evaluation of the biological response is done based on the engendered macroscopic, microscopic and histopathological responses. Typical local biological effects that are evaluated after implantation include capsule formation, inflammatory response, necrosis, vascularization and fatty infiltration ${ }^{87,112}$. Other effects such as fragmentation or degradation of the material, potential tissue ingrowth on the material and formation of new tissue around the material are also taken into account. Implantation is thus used when the local pathological effects due to a medical device need to be determined.

\subsection{Haemocompatibility}

Haemocompatibility testing aims to evaluate the adverse reactions when a material comes into contact with blood. Haemocompatibility is assessed for devices having a direct or indirect contact with blood. Examples of devices tested for haemocompatibility are cannulae, catheters, haemodialysis devices, artificial heart, heart valves prosthesis and stents. The testing is mainly conducted in vitro, but animal testing may, in some cases (e.g. implants), be needed to simulate as closely as possible the conditions of clinical use. The interactions of devices with blood are commonly assessed by evaluating haemolysis, thrombosis, coagulation, platelets and haematology ${ }^{88,113}$. The selection of the tests, as well as the animal model (pigs, dogs, sheep ...), depends on the category to which the medical device belongs. On the other hand, depending on what is aimed to be assessed, different techniques may be used for investigation: imaging of the device to assess thrombosis, measurement of blood plasma level to evaluate coagulation, differential blood cell counting to determine blood cell physical damages... Since a variety of tests and evaluation methods are available for haemocompatibility testing, the selected investigation procedures have to be carefully selected and defined for each specific device to be assessed ${ }^{88}$.

\section{General limitations of animal testing and specific limitations of animal testing relevant to toxicological studies}

Toxicological studies constitute the basis of medical devices safety assessment and guide the evaluation of medical devices biocompatibility within a regulatory framework. Even though in vitro testing is part of the evaluation, the prediction of the potential effects of a medical device on human health is

\footnotetext{
${ }^{109}$ OECD (Organisation for Economic Co-operation and Development), Test No. 414: Prenatal Development Toxicity Study (2001)

${ }^{110}$ OECD (Organisation for Economic Co-operation and Development), Test No. 415: One-Generation Reproduction Toxicity Study (1983)

${ }^{111}$ OECD (Organisation for Economic Co-operation and Development), Test No. 416: Two-Generation Reproduction Toxicity (2001)

112 da Silva Mendes P. R. Histological study on acute inflammatory reaction to polyurethane-coated silicone implants in rats, Acta Cirúrgica Brasileira (2008), Vol. 23(1), 93-101

${ }^{113}$ Yau J. W. et al., Mechanism of catheter thrombosis: comparison of the antithrombotic activities of fondaparinux, enoxaparin, and heparin in vitro and in vivo, Blood (2011), Vol. 18(25), 6667-6674

110 Derecho Animal. Forum of Animal Law Studies, vol. 10/1
} 
primarily based on the results of in vivo testing ${ }^{114}$. From a general point of view, the legitimacy and feasibility of animal experimentation for toxicological studies is currently challenged by issues that are common to numerous animal testing procedures, i.e. ethical and experiment methodological concerns ${ }^{114,115}$. From a more specific point of view, some aspects relate more specifically to toxicology, as for instance the high cost of toxicological tests and the relevance and usefulness of animal responses in reflecting the biological processes taking place in humans ${ }^{116,117}$. The following section discusses these general and specific limitations of animal testing relevant to toxicological studies.

\subsection{Ethical considerations (general limitation)}

As described in the introduction of sections 2 and 3, animals have been largely used over the past for research purposes. According to Martin L. Stephens and Nina S. Mak, the extensive use of animal for toxicological studies relied on "the rise of animal (mostly rodent) breeding for science in general, the virtual absence of more sophisticated ways of assessing toxicity, and the low status of animals in society"118. In the last decades, the scientific view on the quasi systematic use of animals for testing has evolved and new ways of thinking have emerged. Nowadays, the scientific community is divided based on their approach to animal testing as follow: 1. those who support animal testing, 2. those opposed, and 3. those described as the "trouble-middle" i.e. those concerned about the interests of both humans and animals ${ }^{115}$. The first part claims that there is no ethical concern of using animals as experimental subjects and that the acquisition of scientific knowledge prevails. The second part advocates that animals have inherent values and that they should not be exploited for research. The last part accepts that animal testing is performed but only in some cases which are deemed necessary to contribute to the development of science, and under some specific conditions which align with the ethical responsibilities of the scientific community. A conflict exists thus between the different contemporary ethical views on that topic, debating on the benefits of animal research and the morality of impairing the welfare of laboratory animals and/or killing them ${ }^{119}$. It should be however noted that ethical considerations on that matter does not only rise from scientists but also from the public. According to a survey performed in UK in 2016 by IPSOS MORI on the public attitudes to animal research, $59 \%$ of the interrogated citizens declared that they are bothered by the use of animals in research ${ }^{120}$. Taking into account the public opinion, values and concerns is essential for the establishment of socially accepted scientific practices because modifications or creation of new regulation and policies are often pushed by public engagement ${ }^{121,122}$. The ethical dilemma on the use of animal-based science is thus a contentious ethical topic which does not only affect the scientific community but the society as a whole.

\subsection{Methodological issues (general limitation)}

Another issue with animal testing is that the experiments are often poorly designed, analysed and reported, and conducted with lack of methodological quality ${ }^{114,123}$. This may introduce bias in the studies, i.e. "a systematic error, or deviation from the truth, in the results of a study or the conclusions drawn from it" ${ }^{124}$. Such bias may affect the reliability and reproducibility of the experimental findings and contribute to the failure of animal-based research to replicate in humans ${ }^{124,125,126}$. Types of bias include mainly selection, performance, detection, attrition and reporting bias ${ }^{127}$. Examples of such bias are the lack of randomization

\footnotetext{
${ }^{114}$ Knight A. Systematic Reviews of Animal Experiments Demonstrate Poor Human Clinical and Toxicological Utility, ATLA Alternatives to Laboratory Animals (2007), Vol. 35(6), 641-659

${ }^{115}$ Walsh M. Toxicological Tests on Animals: Ethical Possibilities, Australasian Journal of Ecotoxicology (2002), Vol. 8, 57-61

${ }^{116}$ Hartung T. Food for Thought ... on Animal Tests, ALTEX (2008), 25, 1/08

${ }^{117}$ Hartung T. Toxicology for the twenty-first century, Nature (2009), Vol. 460(9), 208-212

118 Stephens M. L. and Nina S. Mak, History of the 3Rs in Toxicity Testing: From Russell and Burch to 21st Century Toxicology Reducing, Refining and Replacing the Use of Animals in Toxicity Testing (2013), Toxicology 19, 1-43

${ }^{119}$ Knight A. Weighing the Costs and Benefits of Animal Experiments, Altex Proceedings (2012), 1/12, Proceedings of WC8, 289294

${ }^{120}$ Clemence M. and Leaman J. Public attitudes to animal research in 2016, IPSOS MORI (2016)

${ }^{121}$ Ormandy E. H. and Schuppli C. A. Public Attitudes toward Animal Research: A Review, Animals (2014), Vol. 4, 391-408

122 Nuffield Council on Bioethics, The ethics of research involving animals (2005)

123 Pound P. et al. Where is the evidence that animal research benefits humans? British Medical Journal (2004), Vol. 328, 514-517

${ }^{124}$ Mcleod M. R. et al. Risk of Bias in Reports of In Vivo Research: A Focus for Improvement, PLoS Biol (2015), Vol. 13(10), e1002273.

${ }^{125}$ Greek R. and Menache A. Systematic Reviews of Animal Models: Methodology versus Epistemology, International Journal of Medical Sciences (2013), Vol, 10(3), 206-221

${ }^{126}$ Festing M. F. W. and Nevalainen T. The Design and Statistical Analysis of Animal Experiments: Introduction to this Issue, ILAR Journal (2014), Vol. 55(3), 379-382

127 Hooijmans et al. SYRCLE's risk of bias tool for animal studies, BMC Medical Research Methodology (2014), Vol. 14 (43), 1-9
} 
of animals assigned to the trial, inappropriate statistical considerations (sample size) to obtain robust data and "non-blinding" of the outcome investigators ${ }^{123,127,128}$. A concrete example of a bias detected in toxicological studies is the dose of test substance that is administered to the animal. The administered dose is commonly the maximal dose that is tolerated by the animal and is usually significantly higher than the dose intended for humans ${ }^{117}$. Combined to the complexity of dose-response relationship underlying toxicology, this makes the extrapolation of the obtained results highly uncertain ${ }^{129}$. Another important factor that can be too often underestimated by scientists is the conditions of animal husbandry. An article written by Nold and co-authors reported that rodents feeding diet types influenced the responses of animals to test substances by altering sensitivity and tissue vulnerability ${ }^{130}$. Diets have for example a direct impact on the tolerance of animals to carcinogens and this may lead to the drawing of flawed conclusions. The ultimate risk of biased or imprecise results is that clinical trials may be conducted based on unreliable data and this may pose a concrete risk for patients ${ }^{123}$. This additionally raises another concern which is the conduct of animal testing that may not be needed if the results become inconclusive ${ }^{123}$. There is therefore an undeniable need in improving the quality of scientific practices and methodologies currently used within animal experimentation in order to achieve more beneficial animal testing ${ }^{123,124,131}$.

\subsection{Correlation of toxicological studies between animal models and humans (specific limitation)}

The use of animal models, along with their outcome, is nowadays a pivotal concept used to bridge the gap between preclinical and clinical research. Animal testing is described by some scientists as necessary because it is the only way to assess the interactions of a substance or a material with a living organism. This part of the scientific community considers that the results obtained on animals are in most cases relevant for extrapolation to humans and that animal testing contributes to ensure human health and safety ${ }^{125,132}$. This idea is based especially on the claim that humans and animals share close similarities ${ }^{133}$, i.e. that they are biologically and genetically similar ${ }^{6,134}$. However, this is not something that has to be taken for granted. As a matter of fact, various studies point out that animal models can fail in predicting suitably human responses ${ }^{133}$. The main question related to prediction is to what extent are animal models effectively reflecting these responses. Even though similarities between humans and non-human animal species exist, very small differences may lead to significant different biological mechanisms (e.g. cellular functions, cellular pathways...), and consequently different reactions ${ }^{133}$. It has been shown for instance that substances classified as teratogens for humans were not necessary teratogenic for non-human primates, and this despite their close phylogenetic relationship ${ }^{114}$. A review written by Bailey and his colleagues reported indeed that when some known human teratogens were tested on primates, only half of them had a teratogenic effect on one or more primate species ${ }^{135}$. On the other hand, although rodents are also genetically very close to humans (see section 2), the prediction based on rodent models does not seem to do much better ${ }^{136}$. A popular study performed by Olson et al. showed that only $43 \%$ of the toxic effects observed in humans were correctly predicted by tests in rodents, and that among the evaluated tests, cutaneous toxicity exhibited the least concordance between rodents and human toxicity ${ }^{137}$. The described studies demonstrate hence that animals are not always effective models to predict the toxicological effects occurring in humans. Extrapolating the biological responses of a species to another species is in fact particularly delicate and may sometimes even be poorly reliable. Nevertheless, this issue persists when extrapolating data within intraspecies ${ }^{138}$. Indeed, the use of animals from a same species but from different strains may also lead to

\footnotetext{
${ }^{128}$ Cressey D. Poorly designed animal experiments in the spotlight, Nature news, https://www.nature.com/news/poorly-designedanimal-experiments-in-the-spotlight-1.18559 (Webpage accessed on 16 May 2018)

${ }^{129}$ Calabrese E. J. Hormesis: a revolution in toxicology, risk assessment and medicine, European Molecular Biology Organization Reports (2004), Vol. 5, S37-S40

130 Nold J. B. et al. Society of Toxicologic Pathology Position Paper: Diet as a Variable in Rodent Toxicology and Carcinogenicity Studies, Toxicologic Pathology (2001), Vol. 29(5), 585-586

${ }^{131}$ Denayer T. et al. Animal models in translational medicine: Validation and prediction, New Horizons in Translational Medicine (2014), Vol. 2, 5-11

${ }^{132}$ Akhtar A. The Flaws and Human Harms of Animal Experimentation, Cambridge Quarterly of Healthcare Ethics (2015), Vol. 24, 407-419

${ }^{133}$ Greek R. Zoobiquity: What Animals Can Teach Us About Health and the Science of Healing, Animals (2012), Vol. 2, 559-563

${ }^{134}$ Varki A. and Altheide T. K. Comparing the human and chimpanzee genomes: Searching for needles in a haystack, Genome Research (2005), Vol. 15, 1746-1758

${ }^{135}$ Bailey J. et al., The Future of Teratology Research is In Vitro. Biogenic Amines (2005), Vol. 19(2), 97-145

${ }^{136}$ Leist M. and Hartung T. Inflammatory findings on species extrapolations: humans are definitely no $70-\mathrm{kg}$ mice, Archives of Toxicology (2013), Vol. 87, 563-567

137 Olson H. et al., Concordance of the Toxicity of Pharmaceuticals in Humans and in Animals, Regulatory Toxicology and Pharmacology (2000), Vol. 32, 56-67

${ }^{138}$ Uhl E. W. and Warner N. J. Mouse Models as Predictors of Human Responses: Evolutionary Medicine, Current Pathobiology 112 Derecho Animal. Forum of Animal Law Studies, vol. 10/1
} 
different results and conclusions. Not only the animal models itself needs to be carefully selected but also the animals to be used within this model ${ }^{131,139}$. One of the commonly accepted explanations for the described discrepancies is that each species, and even each individual, has specific uptake and metabolism patterns ${ }^{117,123}$. This relies on the complexity and fine nuances of biological systems which result mainly from the mechanisms and outcome of an evolutionary history ${ }^{125,132,140}$. Evolutionary adaptations have induced over time gene mutations and changes in gene regulation and expression, modifying thus the initial conditions. As a consequence, a characteristic manifested in two different lineages does not necessarily correlate with the same mechanisms of this characteristic; and this is also valid within the same species $^{133,140}$. The intrinsic complexity of biological systems constitutes moreover an obstacle to the prediction principle because complex systems have specific properties and it is therefore irrelevant to assess them as if they were simple systems. Justifications for this argumentation was detailed in an article written by Greek and his co-authors in which they described that "complex systems are more than the sum of their parts, thus reductionism will yield an incomplete analysis of a complex system [...]; complex systems exhibit emergence, meaning that new properties of a complex system arise from the interactions of the parts [...]; complex systems are resistant to changes and exhibit redundancy in their components; complex systems exhibit self-organization; complex systems demonstrate responses to perturbations that are nonlinear" and "complex systems are very dependent upon initial conditions (for example, genetic makeup)" (non-exhaustive list) ${ }^{125}$. Those considerations complicate thus considerably the extrapolation between complex systems. Therefore, particular cautions shall always be taken when using animal models for predicting the responses in humans, and awareness shall be raised that straightforward extrapolation may cause misleading and false interpretation ${ }^{141}$.

\subsection{Economic cost of toxicological studies (specific limitations)}

A non-negligible aspect of animal testing is the economic cost of such practice. Fleischer M. reported in 2007 the average prices of some toxicological tests conducted within the EU and Switzerland. Some of the reported tests related to the assessment of medical device safety. The prices for a skin irritation test, for a skin sensitization test (LLNA), for an acute toxicity test (inhalation, rats) and for a carcinogenicity test (rats) for example were evaluated to $1^{\prime} 645 €, 3^{\prime} 959 €, 11^{\prime} 734 €$ and 780 ' $357 €$ respectively ${ }^{142}$. The correlation of these prices to the total test cost per year and per test type is particularly difficult to establish because, unlike the number of animals used for research and scientific purposes ${ }^{2}$, the number of test procedures is not yet officially available ${ }^{143}$. However, in 2014, a group of researchers tried to approximate the trend for some of the EU countries ${ }^{144}$. They reported for example 7'877 procedures for skin sensitization within Denmark, Spain, UK, Poland, Slovakia and Hungary. Taking into account Fleischer's prices and considering that these prices did not increase between 2007 and 2014 (which is quite unlikely), more than 31 million euros would have been used for skin sensitization testing; and this considering only six EU countries (over 28 countries ${ }^{145}$ ). This simple estimation obviously does not aim to evaluate the exact cost of some particular animal tests but to raise awareness on the significant amount of money that is potentially consumed for such testing. For a better accuracy, more recent statistics as well as further factors such as the cost of employment of qualified staff and development of appropriate installations would need to be additionally considered ${ }^{116}$. It is nevertheless clear that animal testing represents a significant financial investment for numerous institutions and industrials; especially when such testing is pushed by regulatory requirements ${ }^{146}$ (see section 4).

\section{Alternatives to animal testing used for toxicological studies}

\footnotetext{
Reports (2015), Vol. 3, 219-223

139 Festing M. F. W. Inbred Strains Should Replace Outbred Stocks in Toxicology, Safety Testing, and Drug Development, Toxicologic Pathology (2010), Vol. 38, 681-690

140 Shanks N. et al., Are animal models predictive for humans? Philosophy, Ethics, and Humanities in Medicine (2009), Vol. 4(2), $1-20$

${ }^{141}$ Garner J. P et al., Introducing Therioepistemology: the study of how knowledge is gained from animal research, LabAnimal (2017), Vol. 46(4), 103-113

${ }^{142}$ Fleischer M. Testing Costs and Testing Capacity According to the REACH Requirements - Results of a Survey of Independent and Corporate GLP Laboratories in the EU and Switzerland, Journal of Business Chemistry (2007), Vol. 4(3), 96-114

${ }^{143}$ The next complete report on the use of animals in the Member States (reporting the number of procedures) will be published by the European Commission in 2019 (http://ec.europa.eu/environment/chemicals/lab_animals/legal_en.htm)

144 Taylor K. and Rego L. EU statistics on animal experiments for 2014, ALTEX (2016) Vol. 33(4), $465-468$

145 European Union, The 28 member countries of the EU, https://europa.eu/european-union/about-eu/countries_en (Wedpage accessed on 31 May 2018)

${ }^{146}$ Bottini A. A. and Hartung T. Food for Thought ... on the Economics of Animal Testing, Altex (2009), 26, 1/09
} 
The traditional approaches used for toxicity evaluation, including the assessment of medical device safety, are nowadays facing scientific, ethical and economical hurdles. These hurdles are some of the main drivers calling for the use of alternatives to animal testing ${ }^{147}$. The development of non-animal technologies that are viable for toxicological studies has thus become a strategic key objective. Scientists from multidisciplinary fields, e.g. biologists, chemists, physicians and clinicians, are currently applying the best of the available scientific and technological knowledge to develop such alternatives. The section hereinafter reviews the most promising approaches being developed within life science engineering and biomedical research to move away from animal testing. This review is limited to methods potentially interesting for the assessment of medical device safety.

\subsection{In vitro and ex vivo human 3D skin models}

Human skin is, as the skin of other mammals, composed of two primary layers: the epidermis and the dermis (Figure 12). The epidermis is mainly constituted by keratinocytes and is covered by a thin superficial layer of lipids and corneocytes that is named stratum corneum ${ }^{148}$. The epidermis and the stratum corneum play an important role for the barrier function of the skin by protecting the body from the external world (i.e. pathogens such as bacteria and viruses, environmental damages such as ultra violet radiation and harmful materials etc.) and by controlling the water and electrolytes permeability ${ }^{148}$. The dermis, beneath the epidermis, is constituted by an extracellular matrix (mainly collagen) in which fibroblasts are embedded ${ }^{149}$. It provides the elasticity and stress of the skin.

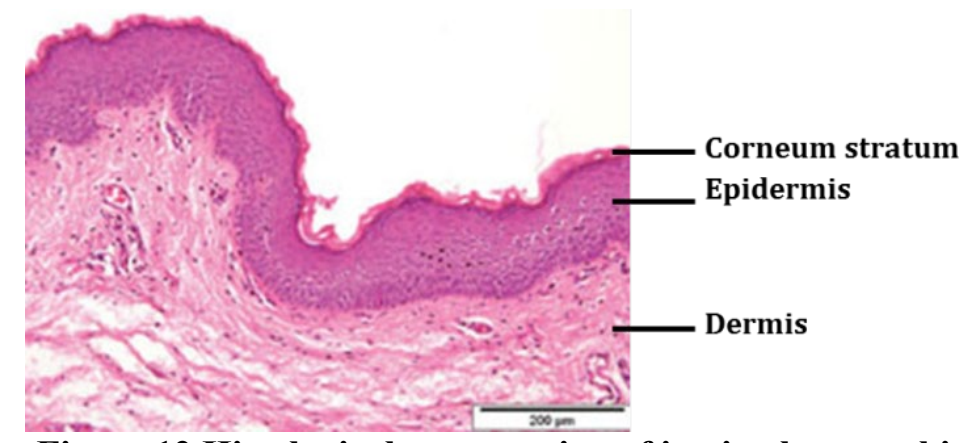

Figure 12 Histological cross section of in vivo human skin.

(Source: adapted from: De Wever B. et al. Overview of human three-dimensional (3D) skin models used for dermal toxicity assessment (Part 1), Household and Personal Care Today (2013), Vol. 8(1), 18-22)

In vitro human skin models are engineered skin constructs consisting of a lattice that contains human epidermal keratinocytes and/or dermal fibroblasts (mono or co-culture) and that intends to reproduce the skin structure ${ }^{149,150}$. One of the reasons for the development of such constructs is the possibility to assess for example cutaneous toxicity without involving animals. Various types of in vitro skin models are currently available on the market (SkinEthic, EST1000 ${ }^{\circledR}$, EpiCS $^{\circledR}$, Phenion $^{\circledR}$, Labcyte $^{\mathrm{TM}}$, Stratatest ${ }^{\circledR} \ldots$ ) but the most well-known (first ones developed) are EpiSkin ${ }^{\mathrm{TM}}$ (L'oréal, France) and EpiDerm ${ }^{\mathrm{TM}}$ (MatTek Corporation, USA $)^{149,150}$. EpiSkin ${ }^{\mathrm{TM}}$ is composed of human keratinocytes forming a multilayer differentiated epidermis on a collagen matrix. EpiDerm ${ }^{\mathrm{TM}}$ is constructed on the same principle but keratinocytes are cultured on a polycarbonate membrane instead of collagen. Both models reproduce many of the important features exhibited by human epidermis (structure, function and expression of markers of epidermal differentiation) and are therefore considered morphologically relevant to assess cutaneous toxicity such as irritation (Figure $13)^{150,151}$. Results obtained on reconstructed skin have been demonstrated to be suitable to reproduce the typical tissue response of human $\operatorname{skin}^{150}$. Moreover, they represent a more predictive and ethical approach

\footnotetext{
${ }^{147}$ Burden N. et al., Testing Chemical Safety: What Is Needed to Ensure the Widespread Application of Non-animal Approaches?, PLOS Biology (2015), Vol. 13(5), e1002156.

${ }^{148}$ Lee S. H. et al., An Update of the Defensive Barrier Function of Skin, Yonsei Medical Journal (2006), Vol. 47(3), 293-306

149 De Wever B. et al,. Overview of human three-dimensional (3D) skin models used for dermal toxicity assessment (Part 1), Household and Personal Care Today (2013), Vol. 8(1), 18-22

${ }^{150}$ De Wever B. et al., Human Skin Models for Research Applications in Pharmacology and Toxicology: Introducing NativeSkin ${ }^{\circledR}$, the "Missing Link" Bridging Cell Culture and/or Reconstructed Skin Models and Human Clinical Testing, Applied in vitro Toxicology (2015), Vol. 1(1), 26-32

${ }^{151}$ Boelsma E. et al., Characterization and Comparison of Reconstructed Skin Models: Morphological and Immunohistochemical Evaluation, Acta Dermato-Venereologica (2000), Vol. 80, 82-88 
than animal testing ${ }^{152}$. Continuous improvement of in vitro skin models is currently being conducted for applications within diverse dermal toxicity tests, including skin irritation, skin sensitization and genotoxicity $^{149,150,152}$.
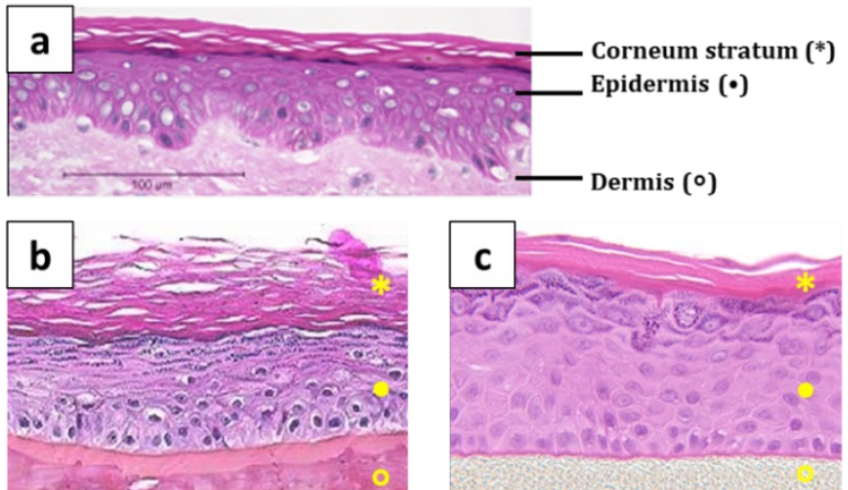

Figure 13 Histological cross section of a) in vivo human skin, b) EpiSkin ${ }^{\mathrm{TM}}$ and c) EpiDerm ${ }^{\mathrm{TM}}$ showing the similar architecture of natural and engineered skin constructs.

(Source: adapted from http://iivs.org/testing-services/assays/dermal/irritation-screening/, Webpage accessed on 4 June 2018)

Another approach which has great potential for skin toxicity evaluation is testing on ex vivo human skin. Ex vivo human skin is an explant harvested from a donor and cultured in laboratory conditions. Up to now, the use of such skin was limited due to the difficulties in maintaining physiological biology of skin, its barrier function and its metabolism for a defined culture duration ${ }^{150,153}$. A novel model recently developed, NativeSkin ${ }^{\circledR}$, seems to overcome these drawbacks (Figure 14) ${ }^{150}$. It is presented as the model of choice to predict more accurately cutaneous effects prior to final clinical evaluation in humans because it encompasses and preserves all the essential characteristics of natural skin, i.e cell population diversity, tissue viability, structure, metabolism and cutaneous barrier properties. This skin culture offers promising testing perspectives but further development is still needed before reaching scientific acceptance.

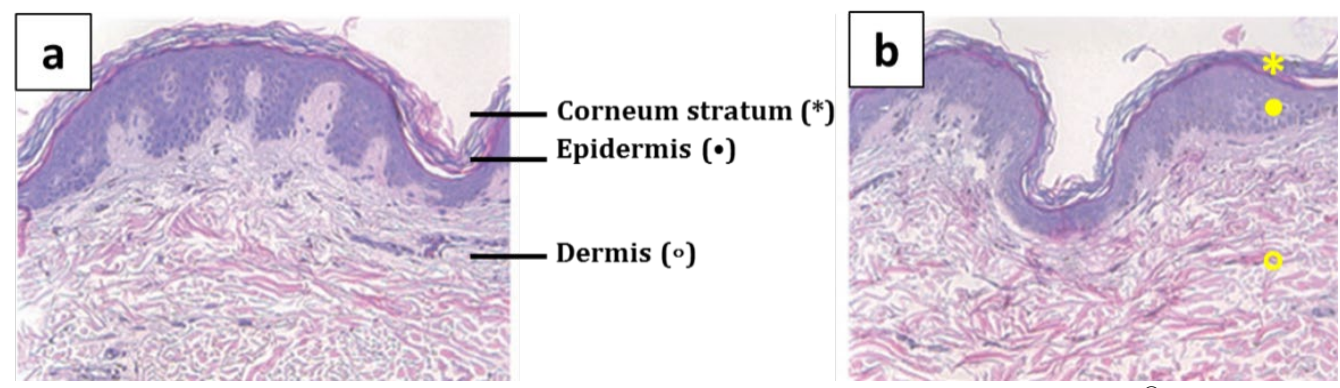

Figure 14 Histological cross section of a) in vivo human skin and b) NativeSkin ${ }^{\circledR}$ showing the similar architecture of natural and engineered skin constructs (after 7 days of ex vivo culture).

(Source: De Wever B. et al. Human Skin Models for Research Applications in Pharmacology and Toxicology: Introducing NativeSkin ${ }^{\circledR}$, the “Missing Link" Bridging Cell Culture and/or Reconstructed Skin Models and Human Clinical Testing, Applied in vitro Toxicology (2015), Vol. 1(1), 26-32)

\subsection{Organs-on-chips}

Organs-on-chips are microfluidic devices developed to culture living cells in continuously perfused micro-meter-sized chambers ${ }^{154}$. The purpose of these devices is to model physiological functions of tissues and organs by summing up "the critical tissue-tissue interfaces, spatiotemporal chemical gradients, and dynamic mechanical micro-environments of living organs" ${ }^{155}$. A variety of tissues and organ systems such as liver, kidney, lung and skin can be modelled (Figure 15) ${ }^{155}$. Micro-physiological systems can be used either to assess a single system (e.g. its basic functions and biological responses) or inter-connected multiple

\footnotetext{
${ }^{152}$ Hewitt N.J. et al., Use of Human In Vitro Skin Models for Accurate and Ethical Risk Assessment: Metabolic Considerations, Toxicological Sciences (2013), Vol. 133(2) 209-217

${ }^{153}$ Nakamura M. et al., Full-tickness human skin explants for testing the toxicity of topically applied chemicals, Journal of Investigative Dermatology (1990), Vol. 95, 325-332

${ }^{154}$ Bhatia S. N. and Ingber D. N. Microfluidic organs-on-chips, Nature Biotechnology (2014), Vol. 32(8), 760-772

${ }^{155}$ Huh D. et al., Micro-engineered physiological biomimicry: Organs-on-Chips, Lab Chip (2012), Vol. 12, 2156-2164
} 
systems (e.g. the interactions between the different interfaces) ${ }^{154,155,156}$. For example, researchers from Korea recently created a skin-on-chip model able to simulate skin oedema ${ }^{157}$; a characteristic of skin irritation which is taken into account when evaluating the irritancy potential of a test substance (see section 5). In comparison to the in vitro skin models described above, this microfluidic device included a vascular layer made of endothelial cells which are involved in the formation of erythema and oedema. The integration of this layer into the system was particularly valuable and enabled thereby the investigation of an additional skin irritation feature that is not considered with engineered human epidermis. Another group of researchers also successfully developed a dynamic multi-organ chip with co-cultures of human artificial liver microtissues and skin biopsies that could be used to assess the systemic toxicity of substances ${ }^{158}$. Thus, organs-onchips offer the great advantage that their design can be tailored and that they can be used to study specific biological phenomena such the ones involved in toxicological adverse reactions. Nevertheless, this perspective is challenged by the complexity of the human body and organ functions, and the difficulty in "integrating multiple organ chips in a physiologically relevant way to model whole human physiology"155,156. Therefore, thorough studies still need to be conducted to support the further development of this tremendous technology that could ultimately be used to replace animal experiments.
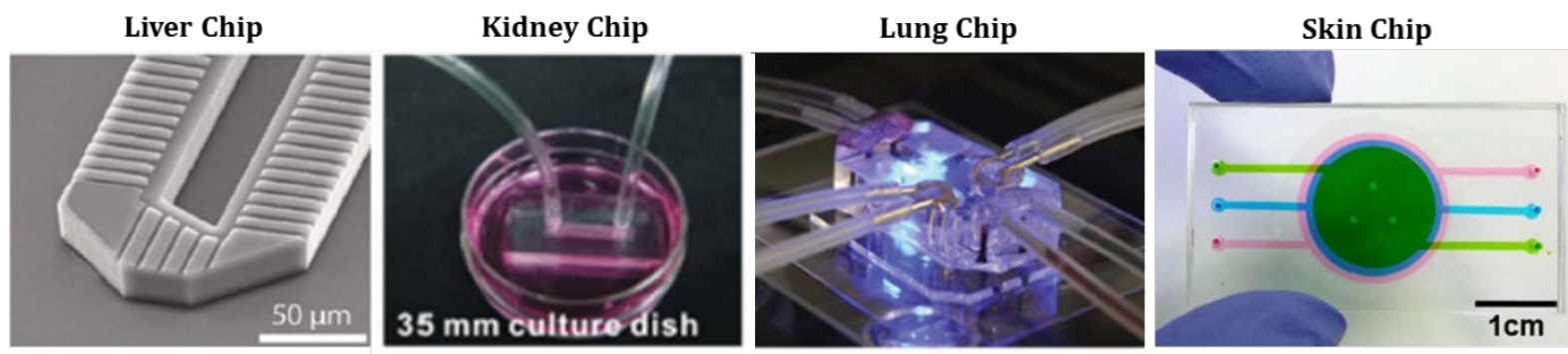

Figure 15 Examples of organ-on-chip models.

(Source: adapted from Huh D. et al., Micro-engineered physiological biomimicry: Organs-on-Chips, Lab Chip (2012), Vol. 12, 2156-2164 and Wufuer M. et al., Skin-on-a-chip model simulating inflammation, edema and drug-based treatment, Nature - Scientific Reports (2016), Vol. 6, 37471 (1-12))

\subsection{Stem cells}

Stem cells are cells able to generate identical copies of them-selves and to differentiate into multiple cell lineage ${ }^{159,160}$. In vitro differentiation consists in inducing a defined cell phenotype (expression of functional characteristics and morphology) from undifferentiated cells by culturing them under specific conditions (culture medium supplemented with growth factors/cytokines/extracellular matrix molecules, application of physical stimuli ... $)^{159,161}$. Typical examples of somatic cells derived from stem cells are

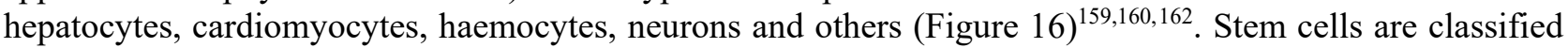
in two categories: the embryonic stem cells and the adult (also known as postnatal or mesenchymal) stem cells. Embryonic stem cells are able to differentiate into most tissues of the organism (pluripotent cells) and are isolated from the blastocyst of mammalian embryos ${ }^{160,161}$. Adult stem cells are able to differentiate only into some tissues of the organism (multipotent cells), meaning that they have lower plasticity than pluripotent cells, and are isolated from diverse tissues of the body ${ }^{160,161}$. Embryonic and adult stem cells from both humans and animals have been demonstrated to be a valuable tool to assess reproductive toxicity, i.e. the effects of substances on fertility, embryo-toxicity/teratogenicity and pre- and postnatal development ${ }^{162,163,164}$. For example, mouse embryonic stem cells can be used to investigate developmental

\footnotetext{
${ }^{156}$ Low L. A. and Tagle D. A. Microphysiological Systems (“Organs-on-Chips”) for Drug Efficacy and Toxicity Testing, Clinical and Translational Science (2017), Vol. 10, 237-239

157 Wufuer M. et al., Skin-on-a-chip model simulating inflammation, edema and drug-based treatment, Nature - Scientific Reports (2016), Vol. 6, 37471 (1-12)

${ }^{158}$ Wagner I. et al., A dynamic multi-organ-chip for long-term cultivation and substance testing proven by 3D human liver and skin tissue co-culture, Lab Chip (2013), Vol. 13, 3538-3547

${ }_{159}$ Davila J. C. et al., Use and Application of Stem Cells in Toxicology, Toxicological Sciences (2004), Vol. 79, 214-223

${ }^{160}$ Luttun A. and Verfaillie C. M. A Perspective on Stem Cells as a Tool for In Vitro Testing, ALTEX (2005), Vol. 22 (Special Issue 2), 388-392

${ }^{161}$ Heng B. C. et al., An overview and synopsis of techniques for directing stem cell differentiation in vitro, Cell and Tissue Research (2004), Vol. 315, 291-303

${ }^{162}$ Liebsch M. et al., Alternatives to animal testing: current status and future perspectives, Archives of Toxicology (2011), Vol. 85, $841-858$

163 Tandon S. and Jyoti S. et al., Embryonic stem cells: An alternative approach to developmental toxicity testing, Journal of Pharmacy And Bioallied Sciences (2012), Vol. 4(2), 96-100

116 Derecho Animal. Forum of Animal Law Studies, vol. 10/1
} 
toxicity. This testing is known as the mouse embryonic stem cell test. It relies on the morphological evaluation of growth inhibition of differentiated and undifferentiated cells (fibroblasts and embryonic stem cells respectively) and the assessment of differentiation inhibition of the embryonic stem cells into cardiomyocytes (cardiac muscle cells) ${ }^{162,163}$. It enables thereby the study of the early developmental processes taking place after fertilization. Human embryonic stem cells can be similarly used for such investigation ${ }^{164}$. On the other hand, human embryonic and adult stem cells can be used to assess the effects of substances on a variety of terminally differentiated cells derived from stem cells. Such somatic cells are for instance used to assess metabolism toxicology and to carry out screening for teratogens ${ }^{159,164,165,166}$. Stem cell models have been proved to be reliable and to provide consistent data with in vivo results ${ }^{162,164}$. Moreover, stem cells are well established cell lines, have an unlimited proliferation ability and are therefore precious experimental ressources ${ }^{162,164}$. Using stem cells for testing seems thus to be a promising strategy to perform toxicity assessment (especially assays related to cytotoxicity, functional toxicity and developmental toxicity).

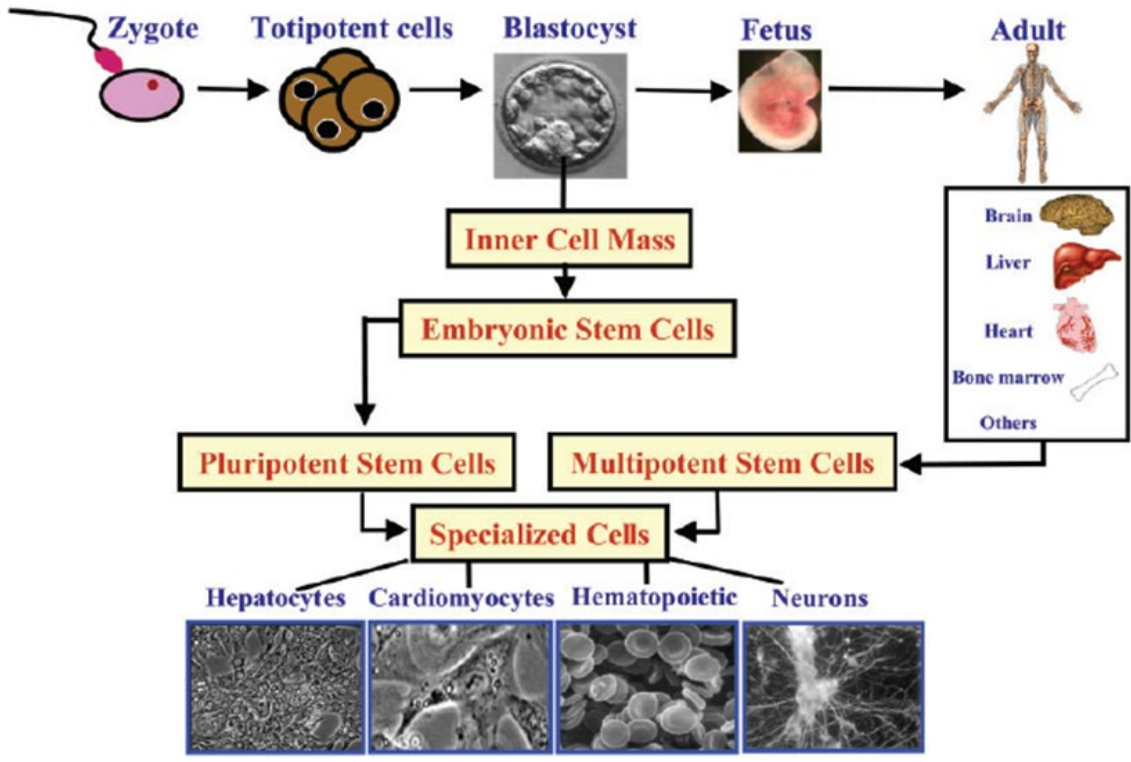

Figure 16 Origin of embryonic stem cells (pluripotent stem cells) and adult stem cells (multipotent stem cells) and examples of somatic cells derived from them.

(Source: adapted from Davila J. C. et al., Use and Application of Stem Cells in Toxicology, Toxicological Sciences (2004), Vol. 79, 214-223)

\subsection{Omics technologies}

Omics technologies encompass the study of gene expression and the cellular constituents controlled by the genome (Figure 17). They refer to the "methods of measuring families of cellular molecules such as ribonucleic acid $\left(\mathrm{RNA}^{167}\right)$, proteins ${ }^{168}$ and intermediary metabolites ${ }^{169,}, 170$. Concretely, five research lines exist within the field of omics technologies:

\footnotetext{
${ }^{164}$ Liu S. et al., Prospects and Frontiers of Stem Cell Toxicology, Stem cells and development (2017), Vol. 26(21), 1528-1539

165 Braam S. R. et al., Prediction of drug-induced cardiotoxicity using human embryonic stem cell-derived cardiomyocytes, Stem Cell Research (2010), Vol. 4, 107-116

166 Zeng X. et al., An In Vitro Model of Human Dopaminergic Neurons Derived from Embryonic Stem Cells: MPP+ Toxicity and GDNF Neuroprotection, Neuro-psychopharmacology (2006), Vol. 31(12), 2708-2715

${ }^{167}$ RNA molecules are molecules that serve as intermediaries on the pathway to proteins. Messenger RNA (mRNA) is conveying genetic information from the cell nucleus to the cytoplasm where the protein synthesis takes place. Alberts B. et al,. Molecular Biology of the Cell. 4th edition. New York: Garland Science (2002). From RNA to Protein. https://www.ncbi.nlm.nih.gov/books/NBK26829/ (Webpage accessed on 08 June 18) / Berg J. M., Tymoczko J. L., Stryer L. Biochemistry. 5th edition. New York: W H Freeman (2002). Chapter 5, DNA, RNA, and the Flow of Genetic Information. https://www.ncbi.nlm.nih.gov/books/NBK21171/ (Webpage accessed on 08 June 18)

${ }^{168}$ Proteins are molecules involved in many biochemical processes (development, functioning ...) and are vital for living organisms. Protein Function, Nature, https://www.nature.com/scitable/topicpage/protein-function-14123348 (Webpage accessed on 08 June 18) ${ }^{169}$ An example of metabolites is cofactors i.e. non-protein compounds that are required for an enzymatic activity.

van der Knaap J. A. and Verrijzer C. P. Undercover: gene control by metabolites and metabolic enzymes, Genes \& Development, Vol. 30, 2345-2369

${ }^{170}$ Aardema M. J. and MacGregor J. T. Toxicology and genetic toxicology in the new era of "toxicogenomics": impact of "-omics" technologies, Mutation Research (2002), Vol. 499, 13-25
} 
- genomics: the "study of the structure, function and expression of all the genes in an organism"171;

- transcriptomics: the "study of the mRNA (messenger RNA ${ }^{167}$ ) within a cell or organism"

- proteomics: the "large-scale study of proteins, including their structure and function within a cell/system/organism" "171;

- metabolomics: the "study of global metabolite profiles in a system (cell, tissue or organism) under a given set of conditions" "171;

- and epigenomics: the "study of reversible heritable changes in gene function that occur without a change in the sequence of nuclear DNA" ${ }^{172}$.

In toxicology, omics technologies can be used for diverse purposes such as the understanding of the mode of action of a toxic substance, the assessment of the genetic variations on toxicological outcomes, the prediction of toxic responses, the evaluation of dose-responses relationship, the comparison of toxic responses between interspecies; among others ${ }^{170,172}$. These studies are performed by assessing for example molecular structure, cellular mechanisms, cellular functional alterations and/or perturbations, DNA damages, cell death, changes in gene/protein expression and others ${ }^{170}$. For instance, a significant milestone in the field was the development of DNA microarrays (also named 'chips'). Chips enable the monitoring of the expression of thousands genes simultaneously and can be used as effective marker of toxicity ${ }^{173,174}$. Omics technologies offer thus the possibility to acquire significant amount of comprehensive data related to toxicological hazards ${ }^{170,172,175}$. They are therefore an extremely valuable approach for the establishment of toxicity investigation procedures implied in risk assessment, as the ones relevant for medical devices safety evaluation.

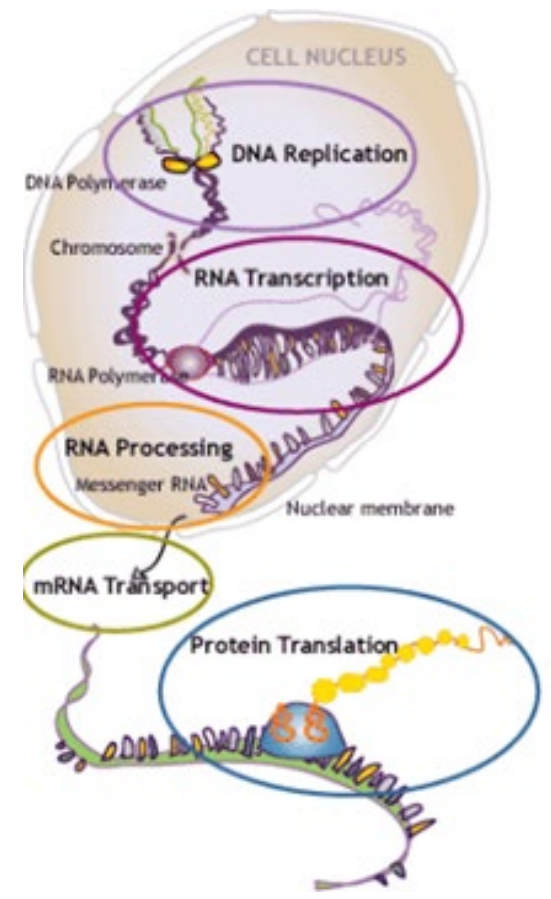

Figure 17 Biological mechanisms governed by the genome and assessed with omics technologies. (Source: https://www.nobelprize.org/educational/medicine/dna/index.html, Webpage accessed on 10 June 2018)

\subsection{In silico modelling techniques}

\footnotetext{
${ }^{171}$ Horgan R. P. and Kenny L. C. 'Omic' technologies: genomics, transcriptomics, proteomics and metabolomics, The Obstetrician \& Gynaecologist (2011), Vol. 13, 189-195

${ }^{172}$ Sauer U. G. et al., The challenge of the application of 'omics technologies in chemicals risk assessment: Background and outlook, Regulatory Toxicology and Pharmacology (2017), Vol. 91, S14-S26

${ }^{173}$ Nuwaysir E. F. et al., Microarrays and Toxicology: The Advent of Toxicogenomics, Molecular Carcinogenesis (1999), Vol. 24, 153-159

${ }^{174}$ Afshari C. A. et al., Application of Complementary DNA Microarray Technology to Carcinogen Identification, Toxicology, and Drug Safety Evaluation, Cancer Research (1999), Vol. 59, 4759-4760

175 Buesen R. et al., Applying 'omics technologies in chemicals risk assessment: Report of an ECETOC workshop, Regulatory Toxicology and Pharmacology (2017), Vol. 91, 1-11
} 
In toxicology, in silico models are models that integrate modern computing and information technology with molecular biology to gain understanding on the molecular mechanisms of toxicity ${ }^{176}$. These models can be applied for example to predict the specific organ toxicity properties of a substance ${ }^{176}$. Various types of in silico tools currently exist but the most prominent ones are the quantitative structure-activity relationships (QSAR) tool, the modelling tools and the kinetics models of substances ${ }^{177}$ (Figure 18). The first tool, QSAR, relies on the description of chemical substances structures by certain parameters (i.e. descriptors) and the use of "a mathematical model that correlates a quantitative measure of chemical structure to either a physical property or a biological effect (e.g. toxic outcome)"176,177. The second tool, modelling, is rather used to determine the likelihood of a substance to trigger a specific response ${ }^{177}$. This is achieved for example by modelling the fit of a substance into a reactive site of a receptor. This application, called receptor modelling, is one of the common uses of this second tool. Finally, the third tool (models of kinetics of substances) refers to the absorption, distribution, metabolism and excretion (ADME) of substances interacting with living organisms ${ }^{176,177}$. This tool is based on the physico-chemical properties of the assessed test substance and on models of various relevant factors (blood flow, organ characteristics ...). According to Hartung T. and Hoffmann S., the added value of in silico technologies is "the objectivity and the tools to appraise our toolbox" as well as the possibility "to combine various approaches in more intelligent ways than a battery of tests" ${ }^{\prime 17}$. These methods are therefore expected to be furthermore developed in the near future with the goal to become relevant and reliable, and ultimately, to replace the acquisition of test data such as with animal testing ${ }^{176,178}$.

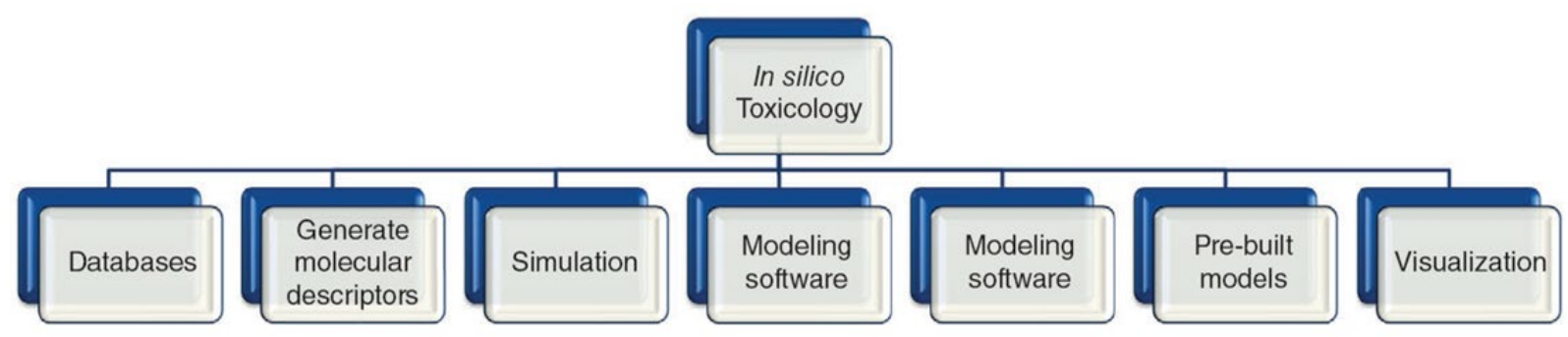

Figure 18 Types of currently available in silico tools.

(Source: Raies A. B. and Bajic V. B. In silico toxicology: computational methods for the prediction of chemical toxicity, WIREs Computational Molecular Science (2016), Vol. 6, 147-172)

\section{Implementation of animal testing alternatives}

Other the past years, more and more attention has been given to the development of alternatives to animal testing. As reflected by the examples listed above, promising approaches arose from the intensive work of the scientific community. Apart from this scientific progress, there is however an essential aspect of alternatives that needs to be considered when talking about the assessment of medical device safety: the regulatory acceptance of newly developed testing methods. The following section describes the most important steps required to establish animal testing alternatives within a regulatory framework and discusses the potential of such alternatives to support the 3Rs Principle.

\subsection{Test method validation}

Test method validation consists in demonstrating "the appropriateness and usefulness of a tool for its intended purpose" 179 . Examples of characteristics that need to be taken into account when conducting method validation are accuracy, precision, repeatability, reproducibility, resolution and robustness ${ }^{180}$. Validation is an essential process needed to ensure the fit-for-purpose of the method and to demonstrate its

\footnotetext{
${ }^{176}$ Raunio H. In silico toxicology: non-testing methods, Frontiers in Pharmacology (2011), Vol. 2, Art. 33, 1-8

${ }_{177}$ Hartung T. and Hoffmann S. Food for Thought ... on In Silico Methods in Toxicology, Altex (2009), Vol. 26(3), 155-166

178 Raies A. B. and Bajic V. B. In silico toxicology: computational methods for the prediction of chemical toxicity, WIREs Computational Molecular Science (2016), Vol. 6, 147-172

${ }^{179}$ Griesinger C. et al., Validation of Alternative In Vitro Methods to Animal Testing: Concepts, Challenges, Processes and Tools, In: Eskes C. and Whelan M. Validation of Alternative Methods for Toxicity Testing. Advances in Experimental Medicine and Biology, Vol. 856, Springer, Cham, 65-132

${ }^{180}$ McGovern J. The 'How' and 'Why' of Test Method Validation. https://www.mdtmag.com/article/2015/09/how-and-why-testmethod-validation (Webpage accessed on 11 June 18)
} 
reliability, as well as to satisfy legal requirements ${ }^{179,181}$. In fact, the Directive on the protection of animals used for scientific purposes (2010/63/EU) expresses the duty of the Commission and the Member States to contribute to the validation of alternative approaches ${ }^{89}$. Moreover, standard ISO 10993-Part 1 on the biological evaluation of medical devices requires the use of in vitro testing methods that are validated ${ }^{83}$. To be validated, a method must fulfil various principles and criteria (e.g. definition of goals, independency of data collection, performance of the methods...) which achievement and assessment commonly requires time $^{182}$. In addition, validation does not always align with the evolution of current practices (i.e. emerging technologies and complex end-points) ${ }^{183}$. Therefore, strategies are being considered to make the process validation more flexible and more efficient (especially costs and time) ${ }^{182,184}$. One example is the "modular approach" of the validation procedure described by Hartung et al. that consists in breaking down the validation process in independent modules and defining the information needed to fulfil each module ${ }^{184}$. Another option is the promotion of meetings and workshops gathering the subject matter experts ${ }^{183}$. Although delicate, validation remains an important task. Given that the outcome of the performed tests is used to make critical decision on public health and safety, it is clear that validation plays a pivotal role in the implementation of animal testing alternatives.

Among the alternatives reported in the previous section, some of them have been already validated for specific applications. This is for example the case of the reconstructed human epidermis test method used to evaluate skin irritation. This method, relying on in vitro models such as EpiSkin ${ }^{\mathrm{TM}}$ and EpiDerm ${ }^{\mathrm{TM}}$, was validated by the European Centre for the Validation of Alternative Methods (ECVAM) to assess the skin irritancy potential of chemicals ${ }^{94,162,185}$. Another approach validated by ECVAM is the embryonic stem cell test. The test was validated based on its ability to differentiate between levels of embryo-toxicity (strong to non-toxicity) caused by chemicals ${ }^{162,186}$. However, in vitro skin irritation and stem cell testing alternatives have not been validated yet for the assessment of medical device safety. Though, some recent studies show that such alternatives present a great potential for that purpose. A recent feasibility study demonstrated for example that engineered skin constructs were capable of detecting low levels of irritants in medical device extracts $^{94}$. Such studies are substantial assets for the implementation of animal testing alternatives for the medical device field because their outcome can be used to justify and boost the initiation of test methods validation for that specific use. Aside from in vitro skin models and stem cells, there are some methods that have not been validated for any applications so far. Relatively new and emerging methods such as the ones referring to organs-on-chips, omics technologies and in silico technologies are some of them ${ }^{156,172,176}$. Nevertheless, their potential is already recognized as enormous for the future and discussions regarding their validation and use are actively taking place ${ }^{172,187}$. A concrete example of such methods is the in silico QSAR tool ${ }^{188,187}$. The validation of specific QSAR models is not an easy task because it can be particularly tricky to carry out ${ }^{189}$ and some essential validation principles still have to be specified (specification of a defined endpoint and establishment of an unambiguous algorithm, as examples) ${ }^{176,187,190}$. Despite these issues, a QSAR Toolbox was created in 2008 due to the tremendous capabilities of that method ${ }^{191}$. This toolbox (software application) contains a variety of models and databases that can be used by governments, chemical industry and other stakeholders to fill the gaps in toxicity data needed for assessing hazards of chemicals ${ }^{191,192}$. It should be however noted that the use of that Toolbox or other available QSAR databases

\footnotetext{
${ }^{181}$ Bridwell H. et al., Perspectives on Method Validation: Importance of Adequate Method Validation, The Quality Assurance Journal (2010), Vol. 13, 72-77

182 Worth A.P. and Balls M. The Principles of Validation and the ECVAM Validation Process, ATLA (2004), Vol. 32 (Suppl. 1), 623-629

${ }^{183}$ European Commission and Joint Research Centre, EURL ECVAM Status Report on the Development, Validation and Regulatory Acceptance of Alternative Methods and Approaches (2017), EUR 28823 EN

${ }^{184}$ Hartung T. et al., A Modular Approach to the ECVAM Principles on Test Validity, ATLA 32 (2004), 467-472

185 OECD (Organisation for Economic Co-operation and Development), Test No. 439: In Vitro Skin Irritation: Reconstructed Human Epidermis Test Method (2015)

${ }^{186}$ Genschow E. et al,. Validation of the Embryonic Stem Cell Test in the International ECVAM Validation Study on Three In Vitro Embryotoxicity Tests, Alternatives to laboratory animals (2004), 209-244

${ }^{187}$ Cherkasow A. et al., QSAR Modeling: Where have you been? Where are you going to?, Journal of Medicinal Chemistry (2014), Vol. 57(12), 4977-5010

${ }_{188}$ Veerasamy R. et al., Validation of QSAR Models - Strategies and Importance, International Journal of Drug Design and Discovery (2011), Vol. 2(3), 511-519

189 Roy K et al., Be aware of error measures. Further studies on validation of predictive QSAR models, Chemometrics and Intelligent Laboratory Systems (2016), Vol. 152, 18-33

190 OECD (Organisation for Economic Co-operation and Development), Guidance document on the validation of (quantitative)structure-activity relationships [(Q)SAR] models, ENV/JM/MONO(2007)2, JT03224782

191 OECD (Organisation for Economic Co-operation and Development), The OECD QSAR Toolbox, http://www.oecd.org/chemicalsafety/risk-assessment/oecd-qsar-toolbox.htm (Webpage accessed on 12 June 2018)

192 OECD (Organisation for Economic Co-operation and Development) \& ECHA (European Chemical Agency) QSAR Toolbox, 
(e.g. JRC QSAR model Database) is under the responsibility of the end-users ${ }^{193}$. In other words, the use of such resources does not guarantee the acceptance of the models for regulatory purposes but it may be used to supplement existing data (e.g. to support new product registration). In fact, QSAR models are claimed to be particularly appropriate for the safety assessment of medical devices. It has been shown for instance that QSAR modelling is effective in predicting the carcinogenicity of colorants contained in medical devices ${ }^{194}$. The ability to evaluate such adverse responses through modelling is relevant for the field since colorants may leach into the body during clinical use and thus pose a risk to the patient. Computational technologies in general may therefore be promising options for the establishment of new strategies for the toxicological evaluation of medical devices. Though, their validation, even if delicate, needs to be performed because it is a valuable asset to achieve regulatory acceptance. Validation is indeed required by science (best scientific practices) and legal requirements, making of validation an essential step for all kind of novel alternatives being developed.

\subsection{Test method standardisation}

Apart from being validated, test methods must be also standardized. Standardization of a test method means that the measurement procedure of this method is established in a standard manner, i.e. that its execution, analysis, interpretation and reporting is performed consistently among different stakeholders. Standards aim to promote the scientific quality of testing, to guarantee the accuracy of testing procedures records, to make relevant the comparison of results between different entities and to encourage the use of specific gold standard techniques ${ }^{195}$. As described in section 4 , the standard operating procedures applicable to the safety assessment of medical devices are provided by the International Standard Organization (ISO) under the ISO 10993 standard series. Currently, no in vitro or computational alternatives are standardized by ISO 10993 to replace the recommended in vivo tests for that specific purpose. In vitro skin irritation testing for instance is mentioned in ISO 10993-Part 10 only as informative data (see Annexe D of the standard) ${ }^{84}$. ISO 10093-Part 10 expressly states: "The in vitro test for skin irritation has so far been validated only for neat chemicals and not for medical device extracts. In order to apply these assays for the testing of irritation potential of medical devices, further validation for this specific area is essential. Certain aspects of the testing of medical devices, such as extraction techniques and possible low concentrations of chemicals in these extracts, can result in adaptations of the testing protocol, such as changing extraction techniques or incubation times" $" 84$. It is thus clear that standardization of any test method is tightly linked to validation. Since validation and standardization are entailed to regulatory acceptance, both procedures are fundamental. However, regulatory is a complex and long procedure ${ }^{172,195,196}$, which also encompasses other crucial tasks (peer reviewing, evaluation of data usefulness for risk assessment procedure, gathering of existing information .... $)^{197}$. Therefore, significant effort and amount of time are commonly needed to introduce new alternatives within a regulatory framework.

\subsection{Animal testing alternatives and $3 R$ R Principle}

Currently, the 3Rs Principle (replacement, reduction, refining) is applied within the medical device safety regulatory framework as follow:

- Standardized animal testing procedures (refining) ( $^{84,85,86,87,88}$ - to promote good science and ensure that specific testing conditions are used, setting the basis of animal welfare practices

- Definition of sample size (reduction) $)^{84,85,86,87,88}$ - to reduce to a minimum the number of animals used while obtaining relevant scientific data

\footnotetext{
The OECD QSAR Toolbox for Grouping Chemicals into Categories, https://www.qsartoolbox.org/ (Webpage accessed on 12 June 2018)

${ }^{193}$ European Commission and Joint Research Centre (JRC), EURL ECVAM Status Report on the Development, Validation and Regulatory Acceptance of Alternative Methods and Approaches (2016), LA-NA-28156-EN-N

${ }^{194}$ Brown R. et al., Use of QSAR Modeling to Predict the Carcinogenicity of Color Additives, Proceedings of ASME Conference on Frontiers in Medical Devices: Applications of Computer Modeling and Simulation (2013), 1-2

${ }^{195}$ Patel J. Does standardisation improve animal testing of medical devices?, Medical Writing (2017), Vol. 26(2), 35-36

196 Sauer U. G. et al,. Local Tolerance Testing Under REACH: Accepted Nonanimal Methods Are Not on Equal Footing with Animal Tests, Alternatives to Laboratory Animals (2016), Vol. 44, 281-299

${ }^{197}$ European Medicines Agency, Guideline on the principles of regulatory acceptance of 3Rs (replacement, reduction, refinement) testing approaches (2016)
} 
- Validated and standardized in vitro procedures (replacement/reduction) ${ }^{198}$ - to avoid or complement animal testing data

- Established animal welfare requirements (refining) ${ }^{92}$ - to guarantee that animal testing is performed humanely (animal care and accommodation), without compromising the scientific quality of research and reproducibility of the results

- Risk assessment and rationalization for using animal testing (reduction) ${ }^{83}$ - to minimize or avoid the use of animal testing if other relevant data are available (replacement)

The stated points demonstrate that the key concept of the 3Rs principle is already implemented within the existing framework of medical devices safety testing. To further strengthen this principle, additional strategies may be considered. For instance, by focussing on the improvement of the quality of animal testing procedures, a better scientific acceptance could be achieved on the one hand, and better animal welfare conditions on the other hand (refining and reduction). Another possible approach would be to promote the development of non-animal testing alternatives (replacement and therefore general reduction). Concretely, considering alternatives described previously, human reconstructed epidermis could be a promising tool to replace rabbit skin irritation test for example, and QSAR prediction to reduce the number of rats used for carcinogenicity testing. Diverse strategies can thus be foreseen to further consolidate the 3Rs principle in the medical devices testing field. Nevertheless, given the special focus of this thesis on the implementation of animal testing alternatives, only final thoughts related to this precise topic are considered below.

As described above, novel non-animal testing alternatives must be validated and standardized to maximize their chance of being regulatory accepted. This tricky and long regulatory acceptance process is a clear hurdle that can slow down the further enforcement of the 3Rs principle by means of these alternatives. Thus, changes are required to achieve regulatory acceptance in a more efficient way. Some potential improvement paths are described below ${ }^{199,200,201,202}$ :

- Effective and transparent explanation of the complex process of regulatory acceptance to achieve a better understanding on the factors influencing regulatory acceptance.

- Improvement of the communication and cooperation between stakeholders, i.e. scientists, regulatory authorities and industries, to optimize the process of regulatory acceptance and support the alignment on set requirements

- Promotion of data sharing between stakeholders to have a comprehensive view on the topic and avoid that studies are unnecessary repeated

- Encouragement of legislation harmonization to avoid regulatory acceptance discrepancies between requirements from different geographical areas

- And finally, grant synergistic, congruent and global effort (time, money, resources, projects ...) for the implementation of non-animal alternatives

Those aspects may optimize the process related to the implementation of animal testing alternatives and contribute to the establishment of a more ethical testing system applied for regulatory purposes. Provided the advanced scientific knowledge available and the pressure set by the global society, there is a clear need for that process to be actively and more successfully enforced.

\section{Conclusion}

The safety assessment of medical devices prior to their marketing is an essential step to guarantee public safety and health. Currently, a significant part of this assessment relies on animal models. Nevertheless, the use of such models can run into a series of difficulties, such as their effectiveness and reliability in correlating human toxicity responses, their price, their time-consumption and their ethical concern. Due to these issues, non-animal alternatives have started to be developed to bypass animal testing.

\footnotetext{
198 ISO 10993-5, Biological evaluation of medical devices - Part 5: Tests for in vitro cytotoxicity, International Organization for Standardization (2009)

${ }_{199}$ Schiffelers W. A. M.-J. et al., Regulatory Acceptance and Use of 3R Models: a Multilevel Perspective, ALTEX (2012), Vol. 29(3), 287-300

${ }^{200}$ Schiffelers W. A. M.-J. et al., Regulatory acceptance and use of 3R models for pharmaceuticals and chemicals: Expert opinions on the state of affairs and the way forward, Regulatory Toxicology and Pharmacology (2014), Vol. 69(1), 41-48

201 Ashton R. et al,. State of the Art on Alternative Methods to Animal Testing from an Industrial Point of View: Ready for Regulation? ALTEX (2014), Vol. 31(3), 357-363

${ }^{202}$ Knight A. Non-Animal Methodologies within Biomedical Research and Toxicity Testing, Altex (2008), Vol. 25(3), 213-231

122 Derecho Animal. Forum of Animal Law Studies, vol. 10/1
} 
The development of such alternatives constitutes an inter-disciplinary field involving scientists with various backgrounds (physicians, biologists, chemists, mathematicians ...) and offers valuable testing perspectives for the future. In fact, these alternatives are claimed to be cheaper, faster, ethical and more reliable than their animal counterparts. The most promising approaches are mainly based on tissue and cell culture, microtechnologies and computational modelling. However, the tricky validation, standardization and regulatory acceptance of these strategies make their implementation within the regulatory framework of medical devices particularly difficult. To boost their use within this context, primordial concepts shall be collectively enforced: cooperation, coordination, communication and most of all, commitment of all stakeholders (scientists, regulatory approval bodes and industries). Knowing that animal studies may paint a misleading picture due to their low capability in predicting human responses and consequently pose a risk to patients, it became clear that the successful implementation of non-animal alternatives should be considered as a key priority and that the resources and effort needed to achieve this goal must be engaged without further delay.

\section{Bibliography}

- Aardema M. J. and MacGregor J. T. Toxicology and genetic toxicology in the new era of "toxicogenomics": impact of "-omics" technologies, Mutation Research (2002), Vol. 499, 13-25

- Abel J. et al., On the removal of diffusible substances from the circulating blood of living animals by dialysis, Journal of Pharmacology and Experimental Therapeutics January (1914), Vol. 5(3), 275316

- Afshari C. A. et al., Application of Complementary DNA Microarray Technology to Carcinogen Identification, Toxicology, and Drug Safety Evaluation, Cancer Research (1999), Vol. 59, 4759-4760

- Akhtar A. The Flaws and Human Harms of Animal Experimentation, Cambridge Quarterly of Healthcare Ethics (2015), Vol. 24, 407-419

- Alberts B. et al,. Molecular Biology of the Cell. 4th edition. New York: Garland Science (2002). From RNA to Protein. https://www.ncbi.nlm.nih.gov/books/NBK26829/ (Webpage accessed on 08 June 18)

- Aquilina O. A brief history of cardiac pacing, Images in Paediatric Cardiology - Journals (2006), Vol. $8(2), 17-81$

- Ashton R. et al,. State of the Art on Alternative Methods to Animal Testing from an Industrial Point of View: Ready for Regulation? ALTEX (2014), Vol. 31(3), 357-363

- Austad S. N., Candidate Bird Species for Use in Aging Research, ILAR Journal (2011), Vol. 52(1), 89-96

- Bailey J. et al., The Future of Teratology Research is In Vitro. Biogenic Amines (2005), Vol. 19(2), 97-145

- Bains P. et al., John Hopps and the pacemaker: A history and detailed overview of devices, indications, and complications, BCMedical Journal (2017), Vol. 59(1), 29-37

- Bateson M. and Feenders G., The Use of Passerine Bird Species in Laboratory Research: Implications of Basic Biology for Husbandry and Welfare, ILAR Journal (2010), Vol. 51(4), 395-408

- Berg J. M., Tymoczko J. L., Stryer L. Biochemistry. 5th edition. New York: W H Freeman (2002). Chapter 5, DNA, RNA, and the Flow of Genetic Information. https://www.ncbi.nlm.nih.gov/books/NBK21171/ (Webpage accessed on 08 June 18)

- Bhatia S. N. and Ingber D. N. Microfluidic organs-on-chips, Nature Biotechnology (2014), Vol. 32(8), 760-772

- Botting J. H. Development of Dialysis to Treat Loss of Kidney Function, Animals and Medicine: The Contribution of Animal Experiments to the Control of Disease, Cambridge: Open Book Publishers (2015), 79-86

- Bottini A. A. and Hartung T. Food for Thought ... on the Economics of Animal Testing, Altex (2009), 26, 1/09

- Boelsma E. et al., Characterization and Comparison of Reconstructed Skin Models: Morphological and Immunohistochemical Evaluation, Acta Dermato-Venereologica (2000), Vol. 80, 82-88

- Braam S. R. et al., Prediction of drug-induced cardiotoxicity using human embryonic stem cellderived cardiomyocytes, Stem Cell Research (2010), Vol. 4, 107-116

- Bridwell H. et al., Perspectives on Method Validation: Importance of Adequate Method Validation, The Quality Assurance Journal (2010), Vol. 13, 72-77

- Brown R. et al., Use of QSAR Modeling to Predict the Carcinogenicity of Color Additives, 
Proceedings of ASME Conference on Frontiers in Medical Devices: Applications of Computer Modeling and Simulation (2013), 1-2

- Buesen R. et al., Applying 'omics technologies in chemicals risk assessment: Report of an ECETOC workshop, Regulatory Toxicology and Pharmacology (2017), Vol. 91, 1-11

- Burden N. et al., Testing Chemical Safety: What Is Needed to Ensure the Widespread Application of Non-animal Approaches?, PLOS Biology (2015), Vol. 13(5), e1002156

- Busch C. et al., The Chick Embryo as an Experimental System for Melanoma Cell Invasion, PLOS one (2013), Vol. 8(1), e53970

- Calabrese E. J. Hormesis: a revolution in toxicology, risk assessment and medicine, European Molecular Biology Organization Reports (2004), Vol. 5, S37-S40

- Cameron J. S. The prehistory of haemodialysis as a treatment for uraemia, Giornale Italiano di Nefrologia (2016), Vol. 33(S66), ISSN 1724-5590

- Charnley J. The lubrication of animal joints in relation to surgical reconstruction by arthroplasty, Annals of the Rheumatic Diseases (1960), Vol. 19, 10-19

- Cherkasow A. et al., QSAR Modeling: Where have you been? Where are you going to?, Journal of Medicinal Chemistry (2014), Vol. 57(12), 4977-5010

- Choyke P. L. Functional Tumor Imaging With Dynamic Contrast-Enhanced Magnetic Resonance Imaging, Journal of magnetic resonance imaging (2003), Vol. 17, 509-520

- Clemence M. and Leaman J. Public attitudes to animal research in 2016, IPSOS MORI (2016)

- Cressey D. Poorly designed animal experiments in the spotlight, Nature news, https://www.nature.com/news/poorly-designed-animal-experiments-in-the-spotlight-1.18559 (Webpage accessed on 16 May 2018)

- Da Silva Mendes P. R. Histological study on acute inflammatory reaction to polyurethane-coated silicone implants in rats, Acta Cirúrgica Brasileira (2008), Vol. 23(1), 93-101

- Davenport A. Portable and wearable dialysis devices for the treatment of patients with end-stage kidney failure: Wishful thinking or just over the horizon?, Pediatric Nephrology (2015), Vol. 30, 2053-2060

- Davila J. C. et al., Use and Application of Stem Cells in Toxicology, Toxicological Sciences (2004), Vol. 79, 214-223

- Deep A. et al., Mouse models of spinal cord injury and stem cell transplantation, Translational Research in Anatomy 1 (2015), 2-10

- De Haën C. Conception of the First Magnetic Resonance Imaging Contrast Agents: A Brief History, Topics in Magnetic Resonance Imaging (2001), Vol. 12(4), 221-230

- Denayer T. et al., Animal models in translational medicine: Validation and prediction, New Horizons in Translational Medicine (2014), Vol. 2, 5-11

- De Wever B. et al., Human Skin Models for Research Applications in Pharmacology and Toxicology: Introducing NativeSkin ${ }^{\circledR}$, the "Missing Link" Bridging Cell Culture and/or Reconstructed Skin Models and Human Clinical Testing, Applied in vitro Toxicology (2015), Vol. 1(1), 26-32

- De Wever B. et al., Overview of human three-dimensional (3D) skin models used for dermal toxicity assessment (Part 1), Household and Personal Care Today (2013), Vol. 8(1), 18-22

- Diaz Quiror J. F. et al., Spinal cord regeneration: where fish, frogs and salamanders lead the way, can we follow?, Biochemical Journal (2013), Vol. 451, 353-364

- Doiron B. et al., Beta Cell Formation in vivo Through Cellular Networking, Integration and Processing (CNIP) in Wild Type Adult Mice, Current Pharmaceutical Biotechnology (2016), Vol. 17, 376-388

- Eshraghi A. A. et al., The cochlear implant: Historical aspects and future prospects, The Anatomical Record (Hoboken) (2012), Vol. 295(11), 1967-1980

- European Commission, Council Directive, Directive 90/385/EEC on the approximation of the laws of the Member States relating to active implantable medical devices, Council Directive, Official Journal of the European Union (1990), 1990L0385

- European Commission, Council Directive, Directive 93/42/EEC concerning medical devices, Official Journal of the European Union (1993), L 169/1

- European Commission, Council Directive, Directive 98/79/EC on in vitro diagnostic medical devices, Official Journal of the European Union (1998), 1998L0079

- European Commission, Council Directive, Directive 2007/47/EC amending Council Directive 90/385/EEC on the approximation of the laws of the Member States relating to active implantable medical devices, Council Directive 93/42/EEC concerning medical devices and Directive 98/8/EC 
concerning the placing of biocidal products on the market, Official Journal of the European Union (2007),

L 247/21

- European Commission, Council Directive, Directive 2010/63/EU on the protection of animals used for scientific purposes, Official Journal of the European Union (2010), L 276/33

- European Commission, Seventh Report on the Statistics on the Number of Animals used for Experimental and other Scientific Purposes in the Member States of the European Union, COM (2013) 859 final

- European Commission, Sixth Report on the Statistics on the Number of Animals used for Experimental and other Scientific Purposes in the Member States of the European Union, COM(2010) 511 final $/ 2$

- European Commission and Joint Research Centre (JRC), EURL ECVAM Status Report on the Development, Validation and Regulatory Acceptance of Alternative Methods and Approaches (2016), LA-NA-28156-EN-N

- European Commission and Joint Research Centre, EURL ECVAM Status Report on the Development, Validation and Regulatory Acceptance of Alternative Methods and Approaches (2017), EUR 28823 EN

- European Medicines Agency, Guideline on the principles of regulatory acceptance of 3Rs (replacement, reduction, refinement) testing approaches (2016)

- Feneley R. C. L. et al., Urinary catheters: history, current status, adverse events and research agenda, Journal of Medical Engineering and Technology (2015), Vol. 39(8), 459-470

- Feng L. et al., Rabbit monoclonal antibody: potential application in cancer therapy, American Journal of Translational Research (2011), Vol. 3(3), 269-274

- Festing M. F. W. Inbred Strains Should Replace Outbred Stocks in Toxicology, Safety Testing, and Drug Development, Toxicologic Pathology (2010), Vol. 38, 681-690

- Festing M. F. W. and Nevalainen T. The Design and Statistical Analysis of Animal Experiments: Introduction to this Issue, ILAR Journal (2014), Vol. 55(3), 379-382

- Fleischer M. Testing Costs and Testing Capacity According to the REACH Requirements - Results of a Survey of Independent and Corporate GLP Laboratories in the EU and Switzerland, Journal of Business Chemistry (2007), Vol. 4(3), 96-114

- Fox J. et al, The Mouse in Biomedical Research: Normative Biology, Husbandry, and Models (2006), Academic Press

- Frankild S. et al., Comparison of the Sensitivities of the Buehler Test and the Guinea Pig Maximization Test for Predictive Testing of Contact Allergy, Acta Dermato-Venereologica (2000), Vol. 80, 256-262

- Garner J. P et al., Introducing Therioepistemology: the study of how knowledge is gained from animal research, LabAnimal (2017), Vol. 46(4), 103-113

- Genschow E. et al., Validation of the Embryonic Stem Cell Test in the International ECVAM Validation Study on Three In Vitro Embryotoxicity Tests, Alternatives to laboratory animals (2004), 209-244

- Georgi B. et al., From Mouse to Human: Evolutionary Genomics Analysis of Human Orthologs of Essential Genes, PLoS Genetics (2013), Vol 9(5), e1003484

- Geva T. Magnetic Resonance Imaging: Historical Perspective, Journal of Cardiovascular Magnetic Resonance (2006), Vol. 8, 573-580

- Gomez P. F. and Morcuende J. A historical and economic perspective on Sir John Charnley, Chas f. Thackray limited, and the early arthoplasty industry, The Iowa Orthopaedic Journal (2005), Vol. 25, $30-37$

- Gomez P. F. and Morcuende J. A. Early attempts at hip arthroplasty: 1700s to 1950s, Iowa Orthopaedic Journal (2005), Vol. 25, 25-29

- Greek R. and Menache A. Systematic Reviews of Animal Models: Methodology versus Epistemology, International Journal of Medical Sciences (2013), Vol, 10(3), 206-221

- Greek R. Zoobiquity: What Animals Can Teach Us About Health and the Science of Healing, Animals (2012), Vol. 2, 559-563

- Griesinger C. et al., Validation of Alternative In Vitro Methods to Animal Testing: Concepts, Challenges, Processes and Tools, In: Eskes C. and Whelan M. Validation of Alternative Methods for Toxicity Testing. Advances in Experimental Medicine and Biology, Vol. 856, Springer, Cham, 65132 
- Guasch G. and Fuchs E., Mice in the world of stem cell biology, Nature Genetics (2005), Vol. 37(11), 1201-1206

- Gutiérrez-Lovera C. et al., The Potential of Zebrafish as a Model Organism for Improving the Translation of Genetic Anticancer Nanomedicines, Genes (2017), Vol. 8(349), 1-20

- Hartley D. E. H. et al., Bilateral cochlear implantation in the ferret: A novel animal model for behavioural studies, Journal of Neuroscience Methods (2010), Vol. 190(2), 214-228

- Hartung T. Food for Thought ... on Animal Tests, ALTEX (2008), 25, 1/08

- Hartung T. Toxicology for the twenty-first century, Nature (2009), Vol. 460(9), 208-212

- Hartung T. and Hoffmann S. Food for Thought ... on In Silico Methods in Toxicology, Altex (2009), Vol. 26(3), 155-166

- Hartung T. et al., A Modular Approach to the ECVAM Principles on Test Validity, ATLA 32 (2004), $467-472$

- Hayden M. E. and Nacher P. J. History and physical principles of MRI, Magnetic Resonance Imaging Handbook, CRC Press (2016), Chapter 1

- Hayes T. B. et al., Atrazine induces complete feminization and chemical castration in male African clawed frogs (Xenopuslaevis), PNAS (2010), Vol. 107(10), 4612-4617

- Heng B. C. et al., An overview and synopsis of techniques for directing stem cell differentiation in vitro, Cell and Tissue Research (2004), Vol. 315, 291-303

- Hewitt N. J. et al., Use of Human In Vitro Skin Models for Accurate and Ethical Risk Assessment: Metabolic Considerations, Toxicological Sciences (2013), Vol. 133(2) 209-217

- Hill A. J. et al., Zebrafish as a Model Vertebrate for Investigating Chemical Toxicity, Toxicological Sciences (200\%), Vol. 86(1), 6-19

- Hodges M. R. et al., Defects in Breathing and Thermoregulation in Mice with Near-Complete Absence of Central Serotonin Neurons, The Journal of Neuroscience (2008), Vol. 28(10), 2495-2505

- Holmes D. and Martin K., A Bird's-Eye View of Aging: What's in it for Ornithologists?, The Auk (2009), Vol. 126(1), 1-23

- Hooijmans et al., SYRCLE's risk of bias tool for animal studies, BMC Medical Research Methodology (2014), Vol. 14 (43), 1-9

- Horgan R. P. and Kenny L. C. 'Omic' technologies: genomics, transcriptomics, proteomics and metabolomics, The Obstetrician \& Gynaecologist (2011), Vol. 13, 189-195

- Howe K. et al., The zebrafish reference genome sequence and its relationship to the human genome, Nature (2013), Vol. 496, 498-503

- Huh D. et al., Micro-engineered physiological biomimicry: Organs-on-Chips, Lab Chip (2012), Vol. 12, 2156-2164

- ISO 10993-1, Biological evaluation of medical devices - Part 1: Evaluation and testing within a risk management process, International Organization for Standardization (2009)

- ISO 10993-2, Biological evaluation of medical devices - Part 2: Animal welfare requirements, International Organization for Standardization (2006)

- ISO 10993-3, Biological evaluation of medical devices - Part 3: Tests for genotoxicity, carcinogenicity and reproductive toxicity, International Organization for Standardization (2009)

- ISO 10993-4, Biological evaluation of medical devices - Part 4: Selection of tests for interactions with blood, International Organization for Standardization (2017)

- ISO 10993-5, Biological evaluation of medical devices - Part 5: Tests for in vitro cytotoxicity, International Organization for Standardization (2009)

- ISO 10993-6, Biological evaluation of medical devices - Part 6: Tests for local effects after implantation, International Organization for Standardization (2016)

- ISO 10993-10, Biological evaluation of medical devices - Part 10: Tests for irritation and skin sensitization, International Organization for Standardization (2010)

- ISO 10993-11, Biological evaluation of medical devices - Part 11: Tests for systemic toxicity, International Organization for Standardization (2017)

- Jen J. et al., Zebrafish models of cancer: progress and future challenges, Current Opinion in Genetics \& Development (2014), Vol. 24, 38-45

- Kalueff A. V. et al., Zebrafish as an emerging model for studying complex brain disorders, Trends in Pharmacological Sciences (2014), Vol. 35(2), 63-75

- Kang B.-C. et al., Biocompatibility and long-term toxicity of InnoPol implant - a biodegradable scaffold, Experimental Animals (2005), Vol. 54(1), 37-52 
- Kikuchi K., Advances in understanding the mechanism of zebrafish heart regeneration, Stem Cell Research (2014), Vol. 13, 542-555

- Kimber I. et al., Skin sensitization testing in potency and risk assessment, Toxicological Sciences (2001), Vol. 59, 198-208

- Knight A. Non-Animal Methodologies within Biomedical Research and Toxicity Testing, Altex (2008), Vol. 25(3), 213-231

- Knight A. Systematic Reviews of Animal Experiments Demonstrate Poor Human Clinical and Toxicological Utility, ATLA Alternatives to Laboratory Animals (2007), Vol. 35(6), 641-659

- Knight A. Weighing the Costs and Benefits of Animal Experiments, Altex Proceedings (2012), 1/12, Proceedings of WC8, 289-294

- Kornegay N. et al., Canine Models of Duchenne Muscular Dystrophy and Their Use in Therapeutic Strategies, Mammalian Genome (2012), Vol. 23(0), 85-108

- Kretzmer E. A et al., An Animal Model for Cochlear Implants, Archives of Otolaryngology - Head and Neck Surgery (2004), Vol. 130, 499-508

- Kumar T. R. et al., Transgenic Mouse Technology: Principles and Methods, Methods in Molecular Biology (2009), Vol. 590, 335-362

- Lardelli M. Using zebrafish in human disease research: some advantages, disadvantages and ethical considerations, in: Proceedings of 2008 ANZCCART Conference, Auckland, New Zealand, 23-28

- Lee M. et al., Alternatives to In Vivo Draize Rabbit Eye and Skin Irritation Tests with a Focus on 3D Reconstructed Human Cornea-Like Epithelium and Epidermis Models, Toxicological Research (2017), Vol. 33(3), 191-203

- Lee S. H. et al., An Update of the Defensive Barrier Function of Skin, Yonsei Medical Journal (2006), Vol. 47(3), 293-306

- Leist M. and Hartung T. Inflammatory findings on species extrapolations: humans are definitely no 70-kg mice, Archives of Toxicology (2013), Vol. 87, 563-567

- Liebsch M. et al., Alternatives to animal testing: current status and future perspectives, Archives of Toxicology (2011), Vol. 85, 841-858

- Liu S. et al., Prospects and Frontiers of Stem Cell Toxicology, Stem cells and development (2017), Vol. 26(21), 1528-1539

- Luechtefeld T. et al., Analysis of Draize Eye Irritation Testing and its Prediction by Mining Publicly Available 2008-2014 REACH Data, ALTEX (2016), Vol. 33(2), 123-134

- Low L. A. and Tagle D. A. Microphysiological Systems ("Organs-on-Chips") for Drug Efficacy and Toxicity Testing, Clinical and Translational Science (2017), Vol. 10, 237-239

- Luttun A. and Verfaillie C. M. A Perspective on Stem Cells as a Tool for In Vitro Testing, ALTEX (2005), Vol. 22 (Special Issue 2), 388-392

- McGeer M. L., NSAIDs and Alzheimer disease: Epidemiological, animal model and clinical studies, Neurobiology of Aging (2007), Vol. 28, 639-647

- McGovern J. The 'How' and 'Why' of Test Method Validation. https://www.mdtmag.com/article/2015/09/how-and-why-test-method-validation (Webpage accessed on 11 June 18)

- Mcleod M. R. et al., Risk of Bias in Reports of In Vivo Research: A Focus for Improvement, PLoS Biol (2015), Vol. 13(10), e1002273

- Meneton P. et al., Renal physiology of the mouse, American Journal of Physiology - Renal Physiology (2000), Vol. 278 (3), F339-F351

- Mittal T. Pacemakers - A journey through the years, Indian Journal of Thoracic and Cardiovascular Surgery (2005), Vol. 21(3), 236-249

- Moller D. E., New drug targets for type 2 diabetes and the metabolic syndrome, Nature (2001), Vol. $414,821-827$

- Montelieus J. et al., Murine local lymph node assay for predictive testing of allergenicity: two irritants caused significant proliferation, Acta Dermato-Venereologica (1998), Vol. 78, 433-437

- Morais J. M. et al., Biomaterials/Tissue Interactions: Possible Solutions to Overcome Foreign Body Response, American Association of Pharmaceutical Scientists Journal (2010), Vol. 12(2), 188-196

- Mudry A. and Mills M. The Early History of the Cochlear Implant, JAMA Otolaryngology - Head and Neck Surgery (2013), Vol. 139(5), 446-453

- Mural R. J. et al., A Comparison of Whole-Genome Shotgun-Derived Mouse Chromosome 16 and the Human Genome, Science (2002), Vol. 296, 1661-1671 
- Myers D. K. et al., From In Vivo to In Vitro: The Medical Device Testing Paradigm Shift, ALTEX (2017), Vol. 34(4), 479-500

- Nagy L. J. et al., Photorefractive keratectomy in the cat eye: biological and optical outcomes, Journal of Cataract \& Refractive Surgery (2007), Vol. 33(6), 1051-1064

- Nair M. B. et al., Treatment of Goat Femur Segmental Defects with Silica-Coated HydroxyapatiteOne-Year Follow-Up, Tissue Engineering: Part A (2010), Vol. 16 (2), 385-391

- Nakamura M. et al., Full-tickness human skin explants for testing the toxicity of topically applied chemicals, Journal of Investigative Dermatology (1990), Vol. 95, 325-332

- Nold J. B. et al., Society of Toxicologic Pathology Position Paper: Diet as a Variable in Rodent Toxicology and Carcinogenicity Studies, Toxicologic Pathology (2001), Vol. 29(5), 585-586

- Nossaman B. D. et al., History of Right Heart Catheterization: 100 Years of Experimentation and Methodology Development, Cardiology in Review (2010), Vol. 18(2), 94-101

- Nuffield Council on Bioethics, The ethics of research involving animals (2005)

- Nuwaysir E. F. et al., Microarrays and Toxicology: The Advent of Toxicogenomics, Molecular Carcinogenesis (1999), Vol. 24, 153-159

- OECD (Organisation for Economic Co-operation and Development), Guidance document on the validation of (quantitative) structure-activity relationships [(Q)SAR] models, ENV/JM/MONO(2007)2, JT03224782

- OECD (Organisation for Economic Co-operation and Development), Test No. 414: Prenatal Development Toxicity Study (2001)

- OECD (Organisation for Economic Co-operation and Development), Test No. 415: One-Generation Reproduction Toxicity Study (1983)

- OECD (Organisation for Economic Co-operation and Development), Test No. 416: Two-Generation Reproduction Toxicity (2001)

- OECD (Organisation for Economic Co-operation and Development), Test No. 421: Reproduction/Developmental Toxicity Screening Test (2015)

- OECD (Organisation for Economic Co-operation and Development), Test No. 439: In Vitro Skin Irritation: Reconstructed Human Epidermis Test Method (2015)

- OECD (Organisation for Economic Co-operation and Development), Test No. 451: Carcinogenicity Studies (2009)

- OECD (Organisation for Economic Co-operation and Development), Test No. 453: Combined Chronic Toxicity/Carcinogenicity Studies (2009)

- OECD (Organisation for Economic Co-operation and Development), Test No. 474: Mammalian Erythrocyte Micronucleus Test (1997)

- OECD (Organisation for Economic Co-operation and Development), Test No. 475: Mammalian Bone Marrow Chromosome Aberration Test (1997)

- OECD (Organisation for Economic Co-operation and Development), Test No. 488: Transgenic Rodent Somatic and Germ Cell Gene Mutation Assays (2011)

- OECD (Organisation for Economic Co-operation and Development), The OECD QSAR Toolbox, http://www.oecd.org/chemicalsafety/risk-assessment/oecd-qsar-toolbox.htm (Webpage accessed on 12 June 2018)

- OECD (Organisation for Economic Co-operation and Development) \& ECHA (European Chemical Agency) QSAR Toolbox, The OECD QSAR Toolbox for Grouping Chemicals into Categories, https://www.qsartoolbox.org/ (Webpage accessed on 12 June 2018)

- Olson H. et al., Concordance of the Toxicity of Pharmaceuticals in Humans and in Animals, Regulatory Toxicology and Pharmacology (2000), Vol. 32, 56-67

- Ormandy E. H. and Schuppli C. A. Public Attitudes toward Animal Research: A Review, Animals (2014), Vol. 4, 391-408

- Parasuraman S. Toxicological Screening, Journal of Pharmacology and Pharmacotherapeutics (2011), Vol. 2(2), 74-79

- Patel J. Does standardisation improve animal testing of medical devices?, Medical Writing (2017), Vol. 26(2), 35-36

- Pearce A. I. et al., Animal models for implant biomaterial research in bone: a review, European Cells and Materials (2007), Vol. 13, 1-10

- Peng X. et al., Rabbit Models for Studying Human Infectious Diseases, Comparative Medicine (2015), Vol. 65(6), 499-507 
- Physicians committee for responsible medicine, Genetically Modified Mice, PCRM.org (2014), 13187-TOX, 1-3

- Pound P. et al., Where is the evidence that animal research benefits humans? British Medical Journal (2004), Vol. 328, 514-517

- Pramanik S. et al., Chronology of total hip joint replacement and materials development, Trends in Biomaterials and Artificial Organs (2005), Vol. 19(1), 15-25

- Raies A. B. and Bajic V. B. In silico toxicology: computational methods for the prediction of chemical toxicity, WIREs Computational Molecular Science (2016), Vol. 6, 147-172

- Raunio H. In silico toxicology: non-testing methods, Frontiers in Pharmacology (2011), Vol. 2, Art. $33,1-8$

- Rivera A. M. et al., The history of peripheral intravenous catheters: How little plastic tubes revolutionized medicine, Acta Anaesthesiologica Belgica (2005), Vol. 56, 271-282

- Roy K et al., Be aware of error measures. Further studies on validation of predictive QSAR models, Chemometrics and Intelligent Laboratory Systems (2016), Vol. 152, 18-33

- Ryugo D. K. et al., Restoration of Auditory Nerve Synapses in Cats by Cochlear Implants, Science (2005), Vol. 310, 1490-1492

- Sabino B. et al., Effects of Antihypertensive Drugs on Capillary Rarefaction in Spontaneously Hypertensive Rats: Intravital Microscopy and Histologic Analysis, Journal of Cardiovascular Pharmacology (2008), Vol. 51, 402-409

- Santoriello C. et al., Hooked! Modelling human disease in zebrafish, The Journal of Clinical Investigation (2012), Vol. 122(7), 2337-2343

- Santos B. F. et al., Interaction of viper venom serine peptidases with thrombin receptors on human platelets, FEBS Letters 477 (2000), 199-202Vandamme T., Use of rodents as models of human diseases, Journal of Pharmacy and BioAllied Sciences (2014), Vol. 6(1), 2-9

- Sauer U. G. et al., Local Tolerance Testing Under REACH: Accepted Nonanimal Methods Are Not on Equal Footing with Animal Tests, Alternatives to Laboratory Animals (2016), Vol. 44, 281-299

- Sauer U. G. et al., The challenge of the application of 'omics technologies in chemicals risk assessment: Background and outlook, Regulatory Toxicology and Pharmacology (2017), Vol. 91, S14-S26

- Scientific Committee on Health Environmental and Emerging Risks, Final Opinion on 'The need for non-human primates in biomedical research, production and testing of products and devices (update 2017)' (18 May 2017)

- Schiffelers W. A. M.-J. et al., Regulatory Acceptance and Use of 3R Models: a Multilevel Perspective, ALTEX (2012), Vol. 29(3), 287-300

- Schiffelers W. A. M.-J. et al., Regulatory acceptance and use of 3R models for pharmaceuticals and chemicals: Expert opinions on the state of affairs and the way forward, Regulatory Toxicology and Pharmacology (2014), Vol. 69(1), 41-48

- Schuh J. C. L. Medical Device Regulations and Testing for Toxicologic Pathologists, Toxicologic Pathology (2008), Vol. 36, 63-69

- Shanks N. et al., Are animal models predictive for humans? Philosophy, Ethics, and Humanities in Medicine (2009), Vol. 4(2), 1-20

- Shen C. and Zuo Z. Zebrafish as a Model to Study Autism Spectrum Disorder Caused by Environmental Chemicals Exposure, Journal of Alzheimer's Disease \& Parkinsonism (2016), Vol. 6(6), 1000288

- Simeonova R. and Danchev N. Assessment of surgical sutures Polymed ${ }^{\mathbb{R}}$ by intracutaneous irritation test in rabbits, Interdisciplinary Toxicology (2013), Vol. 6(2), 99-102

- Stephens M. L. and Nina S. Mak, History of the 3Rs in Toxicity Testing: From Russell and Burch to 21 st Century Toxicology - Reducing, Refining and Replacing the Use of Animals in Toxicity Testing (2013), Toxicology 19, 1-43

- Stewart A. M. et al., Zebrafish models for translational neuroscience research: from tank to bedside, Trends in Neurosciences (2014), Vol. 37(5), 264-278

- Sumner D. R. et al., Animal models relevant to cementless joint replacement, Journal of Musculoskeletal and Neuronal Interactions (2001), Vol. 1(4), 333-345

- Tandon S. and Jyoti S. et al., Embryonic stem cells: An alternative approach to developmental toxicity testing, Journal of Pharmacy And Bioallied Sciences (2012), Vol. 4(2), 96-100

- Tannenbaum J. and Taylor Bennett B. Russell and Burch's 3Rs Then and Now: The Need for Clarity in Definition and Purpose, Journal of the American Association for Laboratory Animal Science 
(2015), Vol. 54(2), 120-132.

- Taylor K. and Rego L. EU statistics on animal experiments for 2014, ALTEX (2016) Vol. 33(4), 465468

- Uhl E. W. and Warner N. J. Mouse Models as Predictors of Human Responses: Evolutionary Medicine, Current Pathobiology Reports (2015), Vol. 3, 219-223

- Valdes T. I. et al., The chick chorioallantoic membrane as a novel in vivo model for the testing of biomaterials, Journal of Biomedical Materials Research(2002), Vol. 62(2), 273-282

- Van der Knaap J. A. and Verrijzer C. P. Undercover: gene control by metabolites and metabolic enzymes, Genes \& Development, Vol. 30, 2345-2369

- Varki A. and Altheide T. K. Comparing the human and chimpanzee genomes: Searching for needles in a haystack, Genome Research (2005), Vol. 15, 1746-1758

- Veerasamy R. et al., Validation of QSAR Models - Strategies and Importance, International Journal of Drug Design and Discovery (2011), Vol. 2(3), 511-519

- Vergara M.N. and Canto-Soler M. V., Rediscovering the chick embryo as a model to study retinal development, Neural Development (2012), Vol. 7(22), 1-19

- Vienken J. 'Bioengineering for life': a tribute to Willem Johan Kolff, Nephrology Dialysis Transplantation (2009), Vol. 24, 2299-2301

- Wagner I. et al., A dynamic multi-organ-chip for long-term cultivation and substance testing proven by 3D human liver and skin tissue co-culture, Lab Chip (2013), Vol. 13, 3538-3547

- Wallingford J. B. et al., Convergent Extension: The Molecular Control of Polarized Cell Movement during Embryonic Development, Developmental Cell (2002), Vol. 2, 695-706

- Walrath J. C. et al., Genetically Engineered Mouse Models in Cancer Research, Advances in Cancer Research (2010), Vol. 106, 113-164

- Walsh M. Toxicological Tests on Animals: Ethical Possibilities, Australasian Journal of Ecotoxicology (2002), Vol. 8, 57-61

- Weber J. et al., From rabbit antibody repertoires to rabbit monoclonal antibodies, Experimental \& Molecular Medicine (2017), Vol. 49, e305

- WenChao S. et al., Using zebrafish as the model organism to understand organ regeneration, Science China Life Sciences (2015), Vol. 58, 343-351

- Willmore W. G. et al., Purification and properties of glutathione reductase from liver of the anoxiatolerant turtle, Trachemysscriptaelegans, Molecular and Cellular Biochemistry (2007), Vol. 297, 139149

- Wirnitzer U., et al., Systemic toxicity of di-2-ethylhexyl terephthalate (DEHT) in rodents following four weeks of intravenous exposure, Toxicology Letters 205 (2011), 8-14

- Worth A.P. and Balls M. The Principles of Validation and the ECVAM Validation Process, ATLA (2004), Vol. 32 (Suppl. 1), 623-629

- Wufuer M. et al., Skin-on-a-chip model simulating inflammation, edema and drug-based treatment, Nature - Scientific Reports (2016), Vol. 6, 37471 (1-12)

- Yau J. W. et al., Mechanism of catheter thrombosis: comparison of the antithrombotic activities of fondaparinux, enoxaparin, and heparin in vitro and in vivo, Blood (2011), Vol. 118(25), 6667-74

- Yi H. et al., Miniature pigs: a large animal model of cochlear implantation, American Journal of Translational Research (2016), Vol. 8(12), 5494-5502

- Yue F. et al., A comparative encyclopedia of DNA elements in the mouse genome, Nature (2014), Vol 515, 355-364

- Zeng X. et al., An In Vitro Model of Human Dopaminergic Neurons Derived from Embryonic Stem Cells: MPP+ Toxicity and GDNF Neuroprotection, Neuro-psychopharmacology (2006), Vol. 31(12), $2708-2715$ 